\title{
The Enterins: A Novel Family of Neuropeptides Isolated from the Enteric Nervous System and CNS of Aplysia
}

\author{
Y. Furukawa, ${ }^{1}$ K. Nakamaru, ${ }^{1}$ H. Wakayama, ${ }^{1}$ Y. Fujisawa, ${ }^{3}$ H. Minakata, ${ }^{3}$ S. Ohta, ${ }^{2}$ F. Morishita, ${ }^{1}$ \\ O. Matsushima, ${ }^{1}$ L. Li, ${ }^{4}$ E. Romanova, ${ }^{4}$ J. V. Sweedler, ${ }^{4}$ J. H. Park, ${ }^{5}$ A. Romero, ${ }^{5}$ E. C. Cropper, ${ }^{5}$ \\ N. C. Dembrow, ${ }^{5}$ J. Jing, ${ }^{5}$ K. R. Weiss, ${ }^{5}$ and F. S. Vilim ${ }^{5}$ \\ ${ }^{1}$ Department of Biological Science, Faculty of Science, and 2Instrumental Center for Chemical Analysis, Hiroshima \\ University, Higashi-Hiroshima 739-8526, Japan, ${ }^{3}$ Suntory Institute for Bioorganic Research, Shimamoto, Mishima, Osaka \\ 618-8503, Japan, ${ }^{4}$ Department of Chemistry and Beckman Institute, University of Illinois, Urbana, Illinois 61801, and \\ ${ }^{5}$ Department of Physiology and Biophysics, Mount Sinai School of Medicine, New York, New York 10029
}

To identify neuropeptides that have a broad spectrum of actions on the feeding system of Aplysia, we searched for bioactive peptides that are present in both the gut and the CNS. We identified a family of structurally related nonapeptides and decapeptides (enterins) that are present in the gut and CNS of Aplysia, and most of which share the HSFVamide sequence at the $\mathrm{C}$ terminus. The structure of the enterin precursor deduced from cDNA cloning predicts 35 copies of 20 different enterins. Northern analysis, in situ hybridization, and immunocytochemistry show that the enterins are abundantly present in the CNS and the gut of Aplysia. Using matrix-assisted laser desorption/ ionization time-of-flight mass spectrometry we characterized the enterin-precursor processing, demonstrated that all of the precursor-predicted enterins are present, and determined posttranslational modifications of various enterins. Enterin-positive neuronal somata and processes were found in the gut, and enterins inhibited contractions of the gut. In the CNS, the cerebral and buccal ganglia, which control feeding, contained the enterins. Enterin was also present in the nerve that connects these two ganglia. Enterins reduced the firing of interneurons B4/5 during feeding motor programs. Such enterininduced reduction of firing also occurred when excitability of B4/5 was tested directly. Because reduction of B4/5 activity corresponds to a switch from egestive to ingestive behaviors, enterin may contribute to such program switching. Furthermore, because enterins are present throughout the nervous system, they may also play a regulatory role in nonfeeding behaviors of Aplysia.

Key words: enteric nervous system; neuropeptide; mollusc; Aplysia; cDNA cloning; immunohistochemistry; in situ hybridization; MALDI-TOF MS
In the last two decades it has become clear that in addition to classical small molecular weight neurotransmitters, neurons also contain another major class of secreted molecules, the neuropeptides (Strand, 1999). The widespread presence and bioactivity of neuropeptides indicates that one cannot understand how the nervous system functions if classical transmitters are studied alone. Indeed, participating neuropeptides and their actions have to be characterized if a full understanding of neuronal functions is to be achieved. Because of the advantageous features of invertebrate nervous systems, significant progress toward understanding the role of neuropeptides has been made in these systems (Marder et al., 1995; Brezina and Weiss, 1997). One organism in which the identity of various peptides and their involvement in

Received May 1, 2001; revised June 12, 2001; accepted July 19, 2001.

This work was supported by a Grant-in-Aid from the Ministry of Education, Science, Sports and Culture of Japan to O.M. (Grant 10440249). Y.F. was supported by the Sunbor Grant from the Suntory Institute for Bioorganic Research. The support of the National Institute of Neurological Disorders and Stroke through Grant NS31609 to J.V.S., the National Institute of Mental Health through Grants MH50235 and K05MH01427 to K.R.W., and the National Institute on Drug Abuse through Grant DA13330 to F.S.V. are gratefully acknowledged. We are grateful to Dr. Gregg Nagle for the generous gift of the Aplysia cDNA library. Aplysia californica were partially provided by the National Resource for Aplysia at the University of Miami under National Institutes of Health National Center for Research Resources Grant RR10294.

Correspondence should be addressed to Ferdinand S. Vilim, Department of Physiology and Biophysics, Box 1218, Mount Sinai School of Medicine, New York, NY 10029. E-mail: vilim@inka.mssm.edu.

Copyright (ㄷ) 2001 Society for Neuroscience $\quad 0270-6474 / 01 / 218247-15 \$ 15.00 / 0$ several physiological processes has been demonstrated is Aplysia californica. However, even in this extensively studied preparation, a number of observations made on neurons and nerves involved in feeding suggested that several as yet unidentified peptides are present in this system (Li et al., 1998). Because progress toward achieving an understanding of feeding behavior of Aplysia depends in part on identifying the modulatory peptides present in this system, we undertook a search for additional peptides that are present and bioactive in the feeding system of Aplysia.

Classical studies on vertebrates demonstrated that many neuropeptides are present in both the CNS and the gut (Mutt, 1990). This commonality of expression and sometimes function has led to the notion of the gut-brain axis (Gue and Bueno, 1996). Previous work demonstrated that such a commonality of peptide expression is also observed in Aplysia (Lloyd et al., 1988; Fujisawa et al., 1999). The identification of peptides that are present in both the CNS and peripheral organs creates a means for investigating more questions than identification of peptides that are present in only one type of tissue. In this study we used both the gut and the CNS as starting material to identify peptides that are present in both tissues. We used a gut contraction bioassay to guide purification and identified the enterins, a novel family of neuropeptides that are present in both the gut and the CNS. Furthermore, we show that enterins affect the feeding circuitry within the cerebral and buccal ganglia. Finally, we demonstrate that the enterins are also present in other ganglia that are in- 
volved in several other behaviors. Thus enterins may act on a number of distinct neural circuits in the CNS.

\section{MATERIALS AND METHODS}

Animals. Two species of the opisthobranch mollusc Aplysia were used: $A$. kurodai and $A$. californica. Animals were kept in tanks filled with artificial seawater (ASW) that were aerated continuously at $14-15^{\circ} \mathrm{C} . A$. kurodai (50-300 gm) were caught in Hiroshima Bay and Hamada City (the coast of the Sea of Japan) and transported to Hiroshima University on the same day. Some animals were provided from the marine biological station of Tohoku University (Asamushi, Japan). For peptide purification, animals were killed immediately after arrival. For physiological experiments, animals were kept in tanks filled with circulating filtered ASW at $15^{\circ} \mathrm{C}$ and fed with dried sea weed. Specimens of $A$. californica (10-500 gm) were obtained from Aplysia Research Facility (Miami, FL), Pacific Biomarine (Venice, CA), and Marinus Inc. (Long Beach, CA). Several larger animals (up to $1000 \mathrm{gm}$ ) were collected off the Monterey Peninsula between January and July, 1998. Animals were used between 3 and $14 \mathrm{~d}$ of receipt. Large animals (200-500 gm) were used for RNA extraction and matrix-assisted laser desorption/ionization time-of-flight mass spectrometry (MALDI-TOF MS), whereas both large and small $(10-500 \mathrm{gm})$ animals were used for immunocytochemistry and in situ hybridization (ISH). Animals were anesthetized by an injection of isotonic $(390 \mathrm{~mm}) \mathrm{MgCl}_{2}$ equal to $50 \%$ of the body weight of each animal before dissection and removal of desired tissues.

Purification. Digestive tracts (esophagus, crop, triturating stomach, and filter chamber) of $A$. kurodai were isolated from 500 specimens and quickly frozen in liquid nitrogen. Frozen tissues were pulverized in liquid nitrogen, boiled for $10 \mathrm{~min}$ in $4 \%$ acetic acid, and then homogenized with a Waring blender. The homogenate was centrifuged at $10,000 \times g$ for 30 $\min \left(4^{\circ} \mathrm{C}\right)$. The supernatant was subjected to rotary evaporation to condense the extract. The extract was applied to $\mathrm{C} 18$ cartridge columns (Sep-pak C18; Waters Corp., Milford, MA; 12 cc, 2 gm). The columns were washed with $0.1 \%$ trifluoroacetic acid (TFA) and eluted with $50 \%$ methanol/0.1\% TFA. The eluate was evaporated to a small volume in a centrifuge evaporator and subjected to HPLC using a gel filtration column (TSKgel G2000SWXL, $7.8 \times 300 \mathrm{~mm}$; Tosoh, Tokyo, Japan), which was isocratically eluted with $45 \%$ acetonitrile/ $0.1 \%$ TFA at a flow rate of $0.5 \mathrm{ml} / \mathrm{min}$. Fractions were collected every $5 \mathrm{~min}$. The biological activity of each fraction was examined by a bioassay using Aplysia esophagus as described below. The bioactive fraction, which eluted between 20 and $25 \mathrm{~min}$ in the gel-filtration HPLC, was then applied to a reverse-phase column (Inertsil ODS-80A, $10 \times 250 \mathrm{~mm}$; GL Science) and eluted with a linear gradient of $0-100 \%$ acetonitrile/0.1\% TFA in 200 $\min (1 \mathrm{ml} / \mathrm{min})$. Bioactive fractions were subjected to further purification steps using reverse-phase columns (TSKgel ODS-80TM, $4.6 \times 150 \mathrm{~mm}$, and TSKgel ODS-80TS, $4.6 \times 250 \mathrm{~mm}$; Tosoh) and a cation-exchange column (TSKgel SP-5PW, $7.5 \times 75 \mathrm{~mm}$; Tosoh) until single absorbance peaks $(220 \mathrm{~nm})$ were obtained. The CNS ganglia (buccal, cerebral, pleural, pedal, and abdominal ganglia) obtained from the same animals as described above were also frozen for a separate purification experiment. The tissue extract prepared as described above was applied to C18 cartridge columns. The retained material was eluted with $100 \%$ methanol/0.1\% TFA. The eluate was first fractionated by a reverse-phase column (Inertsil ODS-80A, $10 \times 250 \mathrm{~mm}$; GL Science) with a linear gradient of $0-100 \%$ acetonitrile $/ 0.1 \%$ TFA in $200 \mathrm{~min}(1 \mathrm{ml} / \mathrm{min})$. The activities of fractions ( $2 \mathrm{ml}$ each) were examined by a bioassay using the triturating stomach of Aplysia. Bioactive fractions were then further purified as described above. In a preliminary experiment, novel peptides purified from the gut extracts in this study were found to cross-react with an antibody raised against a Mytilus inhibitory peptide (WM1) (Fujisawa et al., 1999). We therefore used ELISA using this antibody to purify additional homologous gut peptides. The methods of the ELISA and extraction of the tissues were the same as those described previously (Fujisawa et al., 1999).

Structural determination. The structural determination was performed as described previously (Fujisawa et al., 1999). Briefly, purified peptides were subjected to amino acid sequence analysis by an automated sequencer (PSQ-1; Shimadzu, Kyoto, Japan). For most peptides, to estimate a C-terminal structure, molecular masses were determined by a fast atom bombardment mass spectrometry (FAB-MS) (SX-102A; JEOL, Tokyo, Japan). On the basis of these results, peptides having predicted structures were synthesized by a conventional solid-phase method by a peptide synthesizer (PSSM-8; Shimadzu, Kyoto, Japan) and purified by a reverse-phase (RP)-HPLC. To confirm the structure, retention times of synthetic and purified peptides were compared on both reverse-phase and cationic-exchange HPLCs. When the molecular mass was not available, both C-terminally amidated and nonamidated peptides were synthesized, and their retention times in HPLC were compared with those of purified peptides.

Cloning. The cDNA encoding the enterin precursor was cloned as described previously (Fujisawa et al., 1999). Standard molecular techniques (Sambrook et al., 1989) were used except where noted. The $A$. californica ganglion cDNA library was a gift of Dr. Gregg Nagle (Marine Biomedical Institute, Galveston, TX). The library, a directional Uni-Zap $\lambda$ phage library (Stratagene, La Jolla, CA), was used as a template for both PCR and conventional hybridization screening. Semi-nested degenerate rapid amplification of cDNA ends (RACE) was performed using two vector primers and antisense degenerate primers designed either to GYSHSFV (CCI ACR AAI SWR TGI SWR TAI CC) or KYGHNFV (CCI ACR AAR TTR TGI CCR TAY TT). PCR was performed in two stages on a Robocycler Gradient 40 thermal cycler (Stratagene) using taq DNA polymerase and dNTPs from Perkin-Elmer (Norwalk, CT). Both stages were cycled 25 times for $30 \mathrm{sec}$ at $95^{\circ} \mathrm{C}, 1 \mathrm{~min}$ at the annealing temperature, and $2 \mathrm{~min}$ at $72^{\circ} \mathrm{C}$. Three separate annealing temperatures $\left(50,54\right.$, and $\left.58^{\circ} \mathrm{C}\right)$ were run in parallel, and a set without the degenerate primer was used as a control. The reactions were hot started and not allowed to cool below $72^{\circ} \mathrm{C}$ between the stages. In the first stage, $10 \mu \mathrm{l}$ reactions containing $0.1 \mu \mathrm{M}$ vector primer (ACC ATG ATT ACG CCA $\mathrm{AG}), 0.1 \mu \mathrm{M}$ degenerate primer, $100 \mu \mathrm{M}$ dNTPs, and $0.1 \mu \mathrm{l}$ of library were hot started with $0.1 \mathrm{U}$ of Taq in $0.5 \mu \mathrm{l}$ of reaction buffer. In the second stage, $50 \mu \mathrm{l}$ of prewarmed $\left(72^{\circ} \mathrm{C}\right)$ reaction mix containing $1 \mu \mathrm{M}$ nested vector primer (AAT TAA CCC TCA CTA AAG), $1 \mu \mathrm{M}$ degenerate primer, and $100 \mu \mathrm{M}$ dNTPs was added to each tube, then hot started again with $1 \mathrm{U}$ of Taq.

The results of the PCR were assessed using Agarose gel electrophoresis, and the highest temperature reactions showing significantly more product than the matched degenerate primerless control were polyethylene glycol precipitated and TA cloned (Invitrogen, Carlsbad, CA). Insert-bearing clones were identified using colony PCR, then cycle sequenced with dye termination. Inserts from promising degenerate clones were isolated and labeled using ${ }^{32} \mathrm{PdCTP}$ and random primers (NEB, Beverly, MA). These probes were then used to screen a library to identify full-length clones. At least two independent clones were sequenced for all regions using a combination of restriction, deletion, and primer walking. Sequence alignments were generated using Geneworks V2.1, and consensus contigs were assembled manually.

Mass spectrometry. Mass spectrometry was performed as described previously (Fujisawa et al., 1999). Briefly, ganglia with intact connectives and commissures were removed, and in some cases a moderate protease treatment (e.g., $1 \%$ Protease type IX for $30-60 \mathrm{~min}$ at $34^{\circ} \mathrm{C}$ ) was used to soften the connective tissues before cell dissection. Extracellular salts were removed with washes of $10 \mathrm{mg} / \mathrm{ml}$ of 2,5-dihydroxybenzoic acid (ICN Pharmaceuticals, Costa Mesa, CA), and specific cells were identified and isolated based on the immunostaining results. Tungsten needles were used to isolate individual or group of cells onto a MALDI sample plate containing $0.5 \mu \mathrm{l}$ of matrix solution. After drying at ambient temperature, samples were either frozen for future analysis or analyzed immediately.

Mass spectra were obtained using a Voyager DE-STR mass spectrometer equipped with delayed ion extraction (PE Biosystems, Framingham, MA). A pulsed nitrogen laser $(337 \mathrm{~nm})$ was used as the desorption/ ionization source, and positive-ion mass spectra were acquired using both the linear and reflectron mode. Each representative mass spectrum shown is an average of 128-256 laser pulses. Mass calibration was performed internally using identified peptides FMRFamide $(\mathrm{m} / \mathrm{z} 599.33)$ and $\operatorname{SCP}_{\mathrm{A}}(m / z$ 1277.6) as calibrants. Laser power and delay time were optimized for each type of samples [i.e., single cells and cerebropleural connective (HPLC) fractions]. Mass spectral peaks were assigned based on a combination of observed masses and the knowledge of prohormone sequences.

Northern analysis. Northern analysis was performed as described previously (Fujisawa et al., 1999). The buccal, cerebral, pleural, pedal, and abdominal ganglia were separately dissected and pooled from five animals (A. californica). RNA was isolated by the acid-phenol method of Chomcyznski and Sacchi (1987). RNA was fractionated on a 4-morpholinepropanesulfonic acid/formaldehyde 1.5\% Agarose gel and downward transferred (turboblotter; Schleicher \& Schuell, Keene, NH) overnight with $20 \times \mathrm{SSPE}\left(3 \mathrm{M} \mathrm{NaCl}, 0.2 \mathrm{M} \mathrm{NaH}_{2} \mathrm{PO}_{4}, 0.02 \mathrm{M}\right.$ EDTA, pH 7.4) onto positively charged nylon (Biodyne B; Life Technologies, Gaith- 
ersburg, MD). The RNA was UV cross-linked (Stratalinker, Stratagene, La Jolla, CA), then washed with diethyl pyrocarbonate-treated water, and stained with methylene blue $(0.2 \%$ methylene blue $/ 0.3 \mathrm{M}$ sodium acetate, $\mathrm{pH}$ 5.5). The blot was scanned to document the loading and transfer of the RNA. The positions of the lanes and the bands in the RNA marker lane (Novagen, Madison, WI) were noted on the membrane with a \#2 pencil. After complete destaining in $1 \% \mathrm{SDS} / 0.1 \times$ SSPE, the blots were prehybridized (50\% formamide, $7 \%$ SDS, $250 \mathrm{~mm}$ sodium phosphate, $\mathrm{pH} 7.2,10 \mathrm{~mm}$ EDTA, $10 \%$ dextran sulfate) for $1 \mathrm{hr}$ at $50^{\circ} \mathrm{C}$ in a rotary oven (Hybaid, Franklin, MA). The blot was then hybridized with a random primer-labeled (NEB) probe overnight at $50^{\circ} \mathrm{C}$. Washes were performed $2 \times 15 \mathrm{~min}$ at room temperature with $2 \times$ SSPE $/ 0.1 \%$ SDS, then at $50^{\circ} \mathrm{C}$ for $1 \mathrm{hr}$ with $0.1 \times \mathrm{SSPE} / 0.1 \%$ SDS. Blots were wrapped in Saran and exposed to film. Autoradiograms were aligned with the blots, and the positions of the markers were noted. They were then scanned and assembled into final figures using Photoshop 3.0.

Antibodies. The rabbit anti-SCP antibody was a gift from Dr. Richard Scheller (Stanford Medical School, Stanford, CA), and the antibodies to enterin were made in rats as described (Fujisawa et al., 1999). Briefly, the antigen was prepared by coupling APGYSHSFVamide (AnaSpec Inc., San Jose, CA) to BSA (Sigma A0281) using 1-ethyl-3(dimethylaminopropyl)carbodiimide (EDC; Sigma \#E7750). The coupling was performed in a $1 \mathrm{ml}$ volume of $50 \mathrm{~mm} \mathrm{NaH}_{2} \mathrm{PO}_{4}, \mathrm{pH} \mathrm{7.2,}$ containing $10 \mathrm{mg}$ of BSA, $1 \mathrm{mg}$ of peptide, and $25 \mathrm{mg}$ of EDC. The mixture was allowed to react overnight at $4^{\circ} \mathrm{C}$, and then the coupled antigen was purified from the reaction using a Microcon-30 (spinning at $13,800 \times g$ for $30 \mathrm{~min}$ at $4^{\circ} \mathrm{C}$ to concentrate). After the retentate was

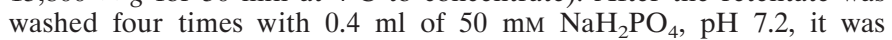
resuspended in $0.5 \mathrm{ml}$ of the same buffer and transferred to a new tube.

Two male Sprague Dawley rats (Teconic, 250-300 gm) were immunized by intraperitoneal injection with either $12.5 \mu \mathrm{l}(\sim 250 \mu \mathrm{g}$, rat 1$)$ or $25 \mu \mathrm{l}(\sim 500 \mu \mathrm{g}$, rat 2$)$ antigen in an emulsion of $0.5 \mathrm{ml}$ PBS and $0.5 \mathrm{ml}$ of Freund's complete adjuvant. At 21 and $42 \mathrm{~d}$ after initial injection, the rats were boosted by intraperitoneal injection with either $6.25 \mu \mathrm{l}(\sim 125$ $\mu \mathrm{g}$, rat 1$)$ or $12.5 \mu \mathrm{l}(\sim 250 \mu \mathrm{g}$, rat 2$)$ antigen in an emulsion of $0.5 \mathrm{ml}$ PBS and $0.5 \mathrm{ml}$ of Freund's incomplete adjuvant. The animals were decapitated at $49 \mathrm{~d}$ after initial injection, and the blood was harvested and processed for serum. Sera were aliquoted, frozen, and lyophilized, or stored at $4^{\circ} \mathrm{C}$ with EDTA (25 mM final) and thimerosal (0.1\% final) added as stabilizers.

Of the two antibodies that we made, rat 1 (which received the lower dose of antigen) gave more specific immunostaining. Rat 1 immunopositive neurons were the most consistent with the in situ hybridizationpositive neurons and the Northern analysis of the distribution of the enterin precursor mRNA in the different ganglia. Therefore, all subsequent immunostaining analysis that we report here was done with the antibody made in rat 1 . Immunostaining with this antibody was abolished by preincubation with $10^{-4} \mathrm{M}$ APGYSHSFVamide (data not shown).

Immunocytochemistry. Immunocytochemistry was performed on $A$. californica as described previously (Vilim et al., 1996; Fujisawa et al., 1999). Tissues were fixed in freshly prepared fixative (4\% paraformaldehyde, $0.2 \%$ picric acid, $25 \%$ sucrose, $0.1 \mathrm{M} \mathrm{NaH}_{2} \mathrm{PO}_{4}, \mathrm{pH} 7.6$ ) for either $3 \mathrm{hr}$ at room temperature or overnight at $4^{\circ} \mathrm{C}$. After washes with PBS to remove the fixative, the ganglia from large animals were desheathed to expose the neurons. Ganglia from small animals $(10-15 \mathrm{gm})$ were processed without desheathing. All subsequent incubations were performed at room temperature with rocking. Tissue was permeabilized and blocked by overnight incubation in blocking buffer (BB) (10\% normal donkey serum, 2\% Triton X-100, 1\% BSA, $154 \mathrm{~mm} \mathrm{NaCl,} 10 \mathrm{~mm}$ $\mathrm{Na}_{2} \mathrm{HPO}_{4}, 50 \mathrm{~mm}$ EDTA, $0.01 \%$ thimerosal, pH 7.4). Primary antibody was diluted 1:250 in $\mathrm{BB}$ and incubated with the tissue for $4-7 \mathrm{~d}$. The tissue was then washed twice a day for 2-3 d with washing buffer (WB) (2\% Triton X-100, 1\% BSA, $154 \mathrm{~mm} \mathrm{NaCl}, 10 \mathrm{~mm} \mathrm{Na}_{2} \mathrm{HPO}_{4}, 50 \mathrm{~mm}$ EDTA, $0.01 \%$ thimerosal, $\mathrm{pH}$ 7.4). After the washes, the tissue was incubated with 1:500 dilution of secondary antibody (lissamine rhodamine donkey anti-rat, Jackson ImmunoResearch, West Grove, PA) for 2-3 d. The tissue was then washed twice with WB for $1 \mathrm{~d}$ and four times with storage buffer ( $1 \% \mathrm{BSA}, 154 \mathrm{~mm} \mathrm{NaCl}, 10 \mathrm{mM} \mathrm{Na}_{2} \mathrm{HPO}_{4}, 50 \mathrm{~mm}$ EDTA, $0.01 \%$ thimerosal, $\mathrm{pH} 7.4$ ) for $1 \mathrm{~d}$. The tissues were then stored at $4^{\circ} \mathrm{C}$ or viewed and photographed on a Nikon microscope equipped with epifluorescence (Morrell Instrument Company, Melville, NY). Negatives were scanned and compiled into figures using Photoshop 3.0.

Backfills. Buccal and cerebral ganglia were isolated and pinned in Sylgard-lined dishes. The cerebral-buccal connective (CBC) was pinned in a silicone grease well, and the tip was washed with distilled water. The backfill solution $(20 \mu \mathrm{l})$, consisting of $1 \%$ biocytin, $2 \%$ low melting Agarose in distilled water was melted at $65^{\circ} \mathrm{C}$ and equilibrated to $37^{\circ} \mathrm{C}$ before application to the CBC. The Agarose, once hardened, served to limit the diffusion of the biocytin. The hardened gel was covered with silicone grease to contain the biocytin during the incubation. The incubation medium for the ganglion was ASW containing 1\% BSA (Sigma \#A9647), $0.1 \%$ amicase (Sigma \#A2427), and 0.03\% dextrose. The incubation medium also contained $0.1 \%$ collagenase, which loosened the sheath during the $24 \mathrm{hr}$ incubation. The ganglia were incubated for $24 \mathrm{hr}$ at $15^{\circ} \mathrm{C}$, then washed several times with ASW before fixation and processing for immunocytochemistry. Processing for immunocytochemistry was the same as described above except that streptavidin-fluorescein was also included with the secondary antibody used to detect the backfilled biocytin. The collagenase treatment greatly facilitated the complete removal of the sheath (even from the nerves), preventing neuronal loss, and allowed for improved penetration of antibodies.

In situ hybridization. Whole-mount in situ hybridization was performed as described previously (Fujisawa et al., 1999). The ganglia and tissues (A. californica) were dissected and pinned out in the desired orientation in $50 \%$ isotonic $\mathrm{MgCl}_{2} / 50 \%$ ASW. All subsequent reagents and solutions used in the in situ hybridization were made with diethyl pyrocarbonatetreated MilliQ water, and care was taken to avoid contamination with RNases. Tissues were fixed in $4 \%$ paraformaldehyde, $0.5 \mathrm{M} \mathrm{NaCl}, 0.1 \mathrm{M}$

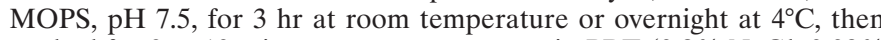
washed for $3 \times 10 \mathrm{~min}$ at room temperature in PBT $(0.8 \% \mathrm{NaCl}, 0.02 \%$ $\mathrm{KCl}, 0.3 \% \mathrm{Na}_{2} \mathrm{HPO}_{4}-12 \mathrm{H}_{2} \mathrm{O}, 0.02 \% \mathrm{KH}_{2} \mathrm{PO}_{4}, 0.1 \%$ Tween $20, \mathrm{pH} 7.4$ ). The tissue was digested with $50 \mu \mathrm{g} / \mathrm{ml}$ of proteinase $\mathrm{K}$ in PBT for $30 \mathrm{~min}$ at $37^{\circ} \mathrm{C}$, then washed again with PBT for $3 \times 10 \mathrm{~min}$ at room temperature. The tissue was post-fixed with $4 \%$ paraformaldehyde in PBT for 1
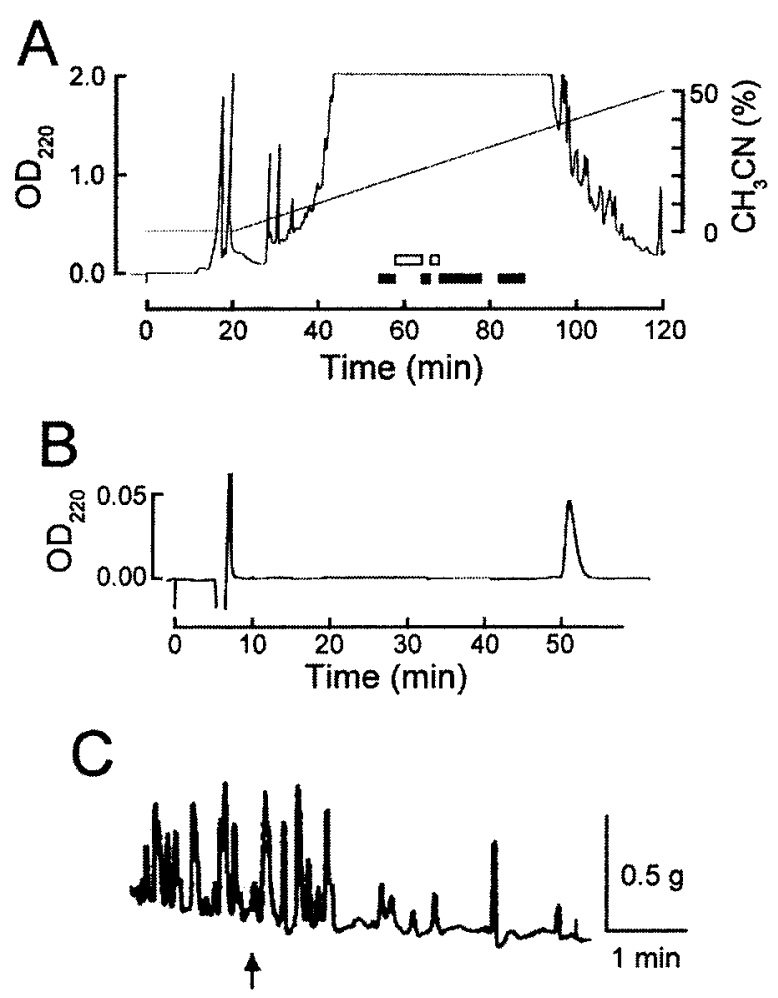

Figure 1. Purification of enterins from gut extracts of $A$. kurodai. A, The second step of HPLC fractionation by a reverse-phase column. Retained material was eluted with a 200 min linear gradient of $0-100 \%$ of acetonitrile $\left(\mathrm{CH}_{3} \mathrm{CN}\right)$ in $0.1 \%$ TFA. As seen in this figure, most retained materials come out within $100 \mathrm{~min}$. Fractions shown to contain bioactive substances are indicated by either black (inhibitory action) or white (excitatory action) bars. The enterins were purified from the fractions shown by a third black bar. B, The final purification step by RP-HPLC. A retained substance was eluted isocratically with $21.5 \% \mathrm{CH}_{3} \mathrm{CN} / 0.1 \%$ TFA. $C$, Biological activity of the purified substance in the triturating stomach of Aplysia. At an arrow, a small aliquot containing the 1/100 of purified substance shown in $B$ was applied to the preparation. 
hr at room temperature, then washed once more with PBT for $3 \times 10 \mathrm{~min}$ at room temperature. The tissue was prehybridized for $1 \mathrm{hr}$ at $42^{\circ} \mathrm{C}$ in hyb-buffer $(5 \times \mathrm{SSC}, 1 \%$ blocking reagent, $50 \mu \mathrm{g} / \mathrm{ml}$ salmon sperm DNA, $0.1 \%$ sarkosyl, $0.02 \%$ SDS) and then hybridized overnight at $42^{\circ} \mathrm{C}$ in hyb-buffer containing $1 \mu \mathrm{g} / \mathrm{ml}$ of the labeled oligo. Oligos (CCT ACA AAG CTG TGY GAA TAG CCA GG) were labeled by tailing with DIG-dUTP/dATP according to the manufacturer's instructions (Roche Molecular Biochemicals, Indianapolis, IN). Unbound probe was washed out with $2 \times \mathrm{SSC} / 0.01 \% \mathrm{SDS}$ for $3 \times 1 \mathrm{hr}$ at $42^{\circ} \mathrm{C}$, then with PBT for $2 \times$ $10 \mathrm{~min}$ at room temperature. The tissue was blocked with $1 \%$ blocking

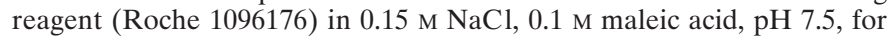
$3 \mathrm{hr}$ at room temperature and then incubated in 1:200 dilution of anti-DIG antibody labeled with alkaline phosphatase (Roche 1093274) in blocking solution for $24 \mathrm{hr}$ at $4^{\circ} \mathrm{C}$. Unbound antibody was washed out with PBT for $5 \times 1 \mathrm{hr}$ at room temperature, then washed with detection buffer ( $0.1 \mathrm{M}$ Tris, $0.1 \mathrm{M} \mathrm{NaCl}, 5 \mathrm{mM} \mathrm{MgCl} \mathrm{ma}_{2}, 10 \mathrm{~mm}$ levamisole) for $2 \times$ $30 \mathrm{~min}$ at room temperature. The signal was developed for $30 \mathrm{~min}$ at room temperature with detection buffer containing $350 \mu \mathrm{g} / \mathrm{ml}$ nitroblue tetrazolium, $175 \mu \mathrm{g} / \mathrm{ml}$ 5-bromo-4-chloro-3-indolyl-phosphate, and $0.1 \%$ Tween 20, and the reaction was then stopped by washing the tissue with PBT containing $1 \mathrm{~mm}$ EDTA (PBTE). The tissues were post-fixed with $4 \%$ paraformaldehyde in PBT overnight at $4^{\circ} \mathrm{C}$. After washing with $\mathrm{PBT}$, tissues were stored protected from light in $50 \%$ glycerol, PBTE at $4^{\circ} \mathrm{C}$. Selected preparations were photographed on a Nikon microscope, and the negatives were scanned and compiled into figures with Photoshop 3.0.

Measurements of muscle contraction. The esophagus and triturating stomach were dissected from animals ( $A$. kurodai). One end of a part of the esophagus $(\sim 1 \mathrm{~cm}$ in length) or a longitudinal strip of the triturating stomach $(\sim 0.5 \mathrm{~cm}$ in width) was immobilized in the bottom of a recording chamber, and the other end was connected to a force-displacement transducer (45196A; NEC San-ei, Tokyo, Japan). The signal was amplified with a strain amplifier (AS1202; NEC San-ei), and then fed into a pen recorder (FBR-251A; TOA Electronics, Tokyo, Japan). The recording chamber $(1.5 \mathrm{ml}$ in volume $)$ was filled with ASW having the following composition (in $\mathrm{mm}$ ): $445 \mathrm{NaCl}, 10 \mathrm{KCl}, 10 \mathrm{CaCl}_{2}, 55 \mathrm{MgCl}_{2}, 10$ Tris-HCl, pH 8.0. After the fractionation by a reversed-phase column, a small volume of each fraction $(1 / 100-1 / 500)$ was dried to remove the organic solvent and redissolved in 20-50 $\mu$ l of ASW. To examine the effects of each fraction, the aliquot was injected into the recording chamber. When the fractions were separated by a cationic exchange column, 5-10 $\mu$ l of each fraction (in $10 \mathrm{~mm}$ phosphate buffer) was applied directly into the chamber. When the effects of synthetic peptides were examined, a small aliquot containing a known concentration of peptide was injected into the chamber. The final concentration of peptides was calculated from the bath volume. To quantify the actions of peptides, we summed the amplitudes of spontaneous contractions for $2 \mathrm{~min}$ before and after the application of peptide. The ratio of the summed amplitudes was used as a parameter reflecting relative change of contractile activities of the gut after peptide application. Statistical significance was determined by one-way ANOVA followed by the Tukey-Kramer test when needed.

CNS electrophysiology. The physiological activity of enterin in the CNS
(A. californica) was tested in a preparation that consisted of the isolated cerebral and buccal ganglia with cerebral-buccal connectives intact. Both ganglia were desheathed to expose the cells of interest. Conventional intracellular recordings were made with glass microelectrodes filled with $2 \mathrm{M} \mathrm{KAc}$ and beveled to 8-15 M $\Omega$. Extracellular recordings were made with suction electrodes that were manufactured from polyethylene tubing. Ganglia were pinned out in a Sylgard-lined dish that had a volume of $\sim 1.5 \mathrm{ml}$. The preparation was continuously perfused with ASW (composition in mM: $460 \mathrm{NaCl}, 10 \mathrm{KCl}, 55 \mathrm{MgCl}_{2}, 11 \mathrm{CaCl}_{2}$, and $10 \mathrm{HEPES}$ buffer, $\mathrm{pH} 7.5$ ) at a rate of $0.3 \mathrm{ml} / \mathrm{min}$, and cooled to $14-17^{\circ} \mathrm{C}$. Peptides were applied by replacing the ASW perfusate with a perfusate consisting of ASW with freshly dissolved peptides.

\section{RESULTS}

\section{Purification of enterins}

Gut extracts eluting between 20 and $25 \mathrm{~min}$ in the initial gel filtration chromatography showed both excitatory and inhibitory actions on the anterior gut (data not shown). These fractions were further purified by RP-HPLC. Figure $1 A$ shows that both inhibitory (white bars) and excitatory (black bars) fractions were detected. The bioactive fractions were further purified by cationic exchange chromatography followed by an additional step of RPHPLC. Sequences of peptides that eluted as single absorbance peaks were determined by Edman sequencing and FAB-MS and then confirmed by co-elution of native and synthetic peptides in HPLC. Some bioactive peptides were not sequenced. Some of the peptides that we isolated and sequenced were identical to previously identified peptides. Specifically, we isolated FMRFamide

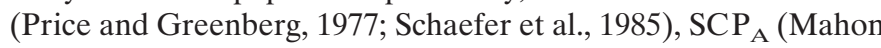
et al., 1985; Lloyd et al., 1987a), myomodulin A (Cropper et al., 1987), buccalin B (Miller et al., 1993b; Vilim et al., 1994), Lysconopressin (Cruz et al., 1987), and GGALFRFamide (Cropper et al., 1994). In addition to some previously identified peptides, we isolated and determined the structure of a number of novel peptides that were structurally related, and all inhibited contractions of the anterior gut. Specifically, using the gut bioassay we purified three peptides from the gut (labeled "Source a" in Table 1) and three peptides from the CNS (labeled "Source b" in Table 1). Because these peptides were all FL/FVamides, an antibody that recognized this motif was used in immunoassays (Fujisawa et al., 1999) to guide purification of eight (labeled "Source c" in Table 1) structurally related peptides from extracts of Aplysia CNS. Four of the structurally related peptides identified using immunoassay were novel, and four corresponded to peptides

Table 1. Enterins biochemically identified from extracts of Aplysia CNS and digestive tract

\begin{tabular}{|c|c|c|c|}
\hline Amino acid sequence analysis (pmol detected) & $\begin{array}{l}\text { Measured } \\
\text { mass }\end{array}$ & $\begin{array}{l}\text { Predicted } \\
\text { structure }\end{array}$ & Source \\
\hline $\mathbf{V}(130)-\mathbf{S}(25)-\mathbf{P}(67)-\mathbf{K}(84)-\mathbf{Y}(78)-\mathbf{G}(62)-\mathbf{H}(23)-\mathbf{N}(59)-\mathbf{F}(27)-\mathbf{V}(9)$ & 1146.4 & VSPKYGHNEVa & $(\mathrm{a}, \mathrm{c})$ \\
\hline $\mathbf{R}(357)-\mathbf{I}(1509)-\mathbf{P}(328)-\mathbf{S}(44)-\mathbf{Y}(550)-\mathbf{G}(81)-\mathbf{H}(228)-\mathbf{S}(*)-\mathbf{F}(27)-\mathbf{L}(95)$ & 1174.6 & RLPSYGHSFLa & (b) \\
\hline $\mathbf{A}(660)-\mathbf{D}(235)-\mathbf{I}(346)-\mathbf{G}(294)-\mathbf{F}(363)-\mathbf{T}(93)-\mathbf{H}(133)-\mathbf{S}(48)-\mathbf{F}(134)-\mathbf{V}(81)$ & 1092.5 & ADLGFTHSFVa & $(\mathrm{a}, \mathrm{c})$ \\
\hline $\mathbf{E}(152)-\mathbf{L}(110)-\mathbf{N}(108)-\mathbf{F}(105)-\mathbf{Q}(83)-\mathbf{H}(46)-\mathbf{A}(50)-\mathbf{F}(42)-\mathbf{V}(18)$ & nd & ELNFQHAFVa & (a) \\
\hline $\mathbf{A}(769)-\mathbf{P}(650)-\mathbf{G}(509)-\mathbf{Y}(626)-\mathbf{S}(156)-\mathbf{H}(261)-\mathbf{S}(81)-\mathbf{F}(132)-\mathbf{V}(92)$ & 963.6 & APGYSHSFVa & $(b, c)$ \\
\hline $\mathbf{V}(668)-\mathbf{P}(634)-\mathbf{G}(502)-\mathbf{Y}(600)-\mathbf{S}(110)-\mathbf{H}(183)-\mathbf{S}(75)-\mathbf{F}(195)-\mathbf{V}(99)$ & 991.5 & VPGYSHSFVa & $(b, c)$ \\
\hline $\mathbf{T}(\quad 55)-\mathbf{P}(178)-\mathbf{G}(152)-\mathbf{Y}(160)-\mathbf{S}(30)-\mathbf{H}(60)-\mathbf{S}(20)-\mathbf{F}(37)-\mathbf{V}(14)$ & 993.2 & TPGYSHSFVa & (c) \\
\hline $\mathbf{Q}(141)-\mathbf{P}(151)-\mathbf{G}(130)-\mathbf{Y}(141)-\mathbf{S}(26)-\mathbf{H}(52)-\mathbf{S}(18)-\mathbf{F}(41)-\mathbf{V}(18)$ & 1020.1 & QPGYSHSFVa & (c) \\
\hline $\mathbf{Q}(71)-\mathbf{P}(77)-\mathbf{S}(13)-\mathbf{F}(87)-\mathbf{G}(45)-\mathbf{H}(28)-\mathbf{S}(8)-\mathbf{F}(21)-\mathbf{V}(10)$ & 1004.3 & QPSFGHSFVa & (c) \\
\hline 71$)-\mathbf{P}(107)-\mathbf{G}(83)-\mathbf{F}(99)-\mathbf{N}(82)-\mathbf{H}(33)-\mathbf{A}(63)-\mathbf{F}(39)-\mathbf{V}(22)$ & 1002.3 & DPGFNHAFVa & (c) \\
\hline
\end{tabular}

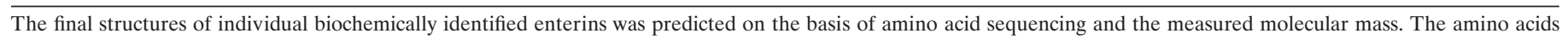

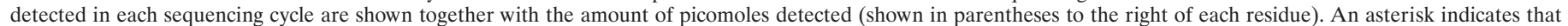

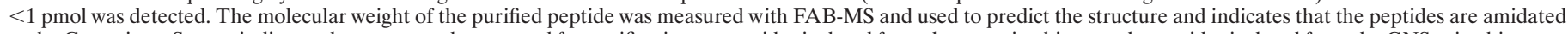

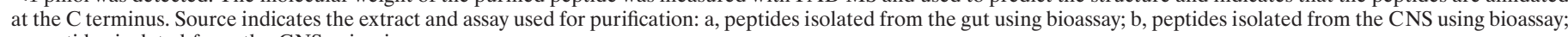
c, peptides isolated from the CNS using immunoassay. 


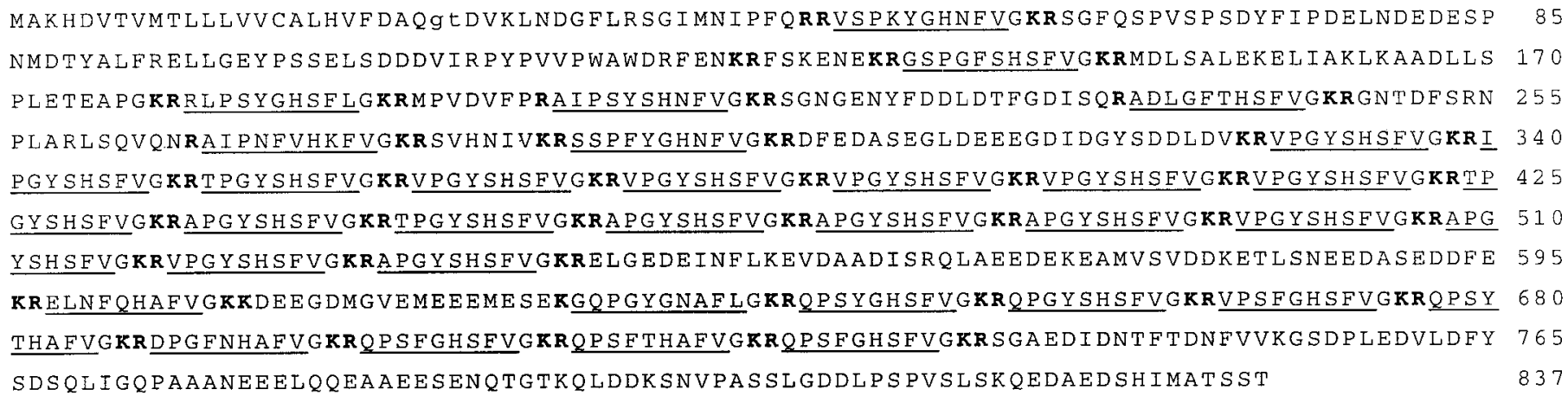

Figure 2. Sequence of the predicted enterin precursor protein. Open reading frame of the cDNA encoding the precursor of APGYSHSFVamide is shown. Amino acids are numbered at right, and predicted amidated enterins are underlined. The enterin precursor predicts 35 copies of 20 different enterins. Monobasic and dibasic cleavage sites are shown in bold, and the predicted signal sequence cleavage site between G(25) and T(26) is shown in lowercase letters.

purified using bioassay (two from the CNS and two from the gut). Thus, using this combination of techniques we identified 10 novel peptides that were structurally related.

We call this novel family of peptides the enterins because they are bioactive on the gut and present in substantial amounts in the gut. Two of the purification steps for one of the enterins are shown in Figure 1, $A$ and $B$. The bioactivity of this enterin on contractions is shown in Figure $1 C$. The structure of this peptide was determined to be ADLGFTHSFVamide. Table 1 summarizes the results of sequencing and FAB-MS and shows the structures of enterins purified from the gut and the CNS extracts of A. kurodai. These enterins possess several structural similarities. All of the enterins are amidated and either nonapeptides or decapeptides. Most of the enterins share a C-terminal sequence of HSFVamide. The second amino acid of nonapeptides (third for decapeptides) is usually proline, and the fourth amino acid of nonapeptides (fifth for decapeptides) is tyrosine or its chemically similar amino acid, phenylalanine.

\section{Cloning of the enterin precursor mRNA}

Semi-nested degenerate RACE was performed using two vector primers and antisense degenerate primers designed either to

Table 2. Summary of mass spectrometric detection of enterins predicted by the precursor

\begin{tabular}{|c|c|c|c|c|c|c|}
\hline $\mathrm{AD}$ & Predicted enterin & $\mathrm{C \#}$ & $\begin{array}{l}{[\mathrm{M}+\mathrm{H}]^{+}} \\
\text {calculated }\end{array}$ & $\begin{array}{l}{[\mathrm{M}+\mathrm{H}]^{+}} \\
\text {observed }\end{array}$ & $\%$ error & ppm \\
\hline $\mathrm{a}$ & VSPKYGHNFVa & 1 & 1146.605 & 1146.607 & 0.00017 & 2 \\
\hline $\mathrm{b}$ & GSPGFSHSFVa & 1 & 1020.490 & 1020.481 & 0.00088 & 9 \\
\hline $\mathrm{c}$ & RLPSYGHSFLa & 1 & 1175.632 & 1175.625 & 0.00059 & 6 \\
\hline d & AIPSYSHNFVa & 1 & 1133.574 & 1133.576 & 0.00017 & 2 \\
\hline $\mathrm{e}$ & ADLGFTHSFVa & 1 & 1092.547 & 1092.53 & 0.00155 & 16 \\
\hline $\mathrm{f}$ & AIPNFVHKFVa & 1 & 1170.678 & 1170.646 & 0.0027 & 27 \\
\hline $\mathrm{g}$ & SSPFYGHNFVa & 1 & 1153.542 & 1153.557 & 0.0013 & 13 \\
\hline $\mathrm{h}$ & VPGYSHSFVa & 8 & 991.500 & 991.479 & 0.0021 & 21 \\
\hline $\mathrm{i}$ & IPGYSHSFVa & 1 & 1005.515 & 1005.489 & 0.00258 & 26 \\
\hline $\mathrm{j}$ & TPGYSHSFVa & 3 & 993.479 & 993.473 & 0.0006 & 6 \\
\hline $\mathrm{k}$ & APGYSHSFVa & 6 & 963.468 & 963.460 & 0.00083 & 8 \\
\hline 1 & PELNFQHAFVa & 1 & 1085.533 & 1085.53 & 0.00028 & 3 \\
\hline $1^{\prime}$ & ELNFQHAFVa & 1 & 1103.563 & 1103.553 & 0.00091 & 9 \\
\hline $\mathrm{m}$ & GQPGYGNAFLa & 1 & 1022.505 & 1022.501 & 0.00039 & 4 \\
\hline $\mathrm{n}$ & PQPSYGHSFVa & 1 & 1003.460 & 1003.451 & 0.0009 & 9 \\
\hline o & PQPGYSHSFVa & 1 & 1003.460 & 1003.451 & 0.0009 & 9 \\
\hline $\mathrm{p}$ & VPSFGHSFVa & 1 & 975.505 & 975.498 & 0.0007 & 7 \\
\hline $\mathrm{q}$ & PQPSYTHAFVa & 1 & 1031.491 & 1031.473 & 0.0017 & 17 \\
\hline $\mathrm{r}$ & DPGFNHAFVa & 1 & 1002.479 & 1002.452 & 0.00269 & 27 \\
\hline $\mathrm{s}$ & PQPSFGHSFVa & 2 & 987.465 & 987.468 & 0.0003 & 3 \\
\hline $\mathrm{t}$ & PQPSFTHAFVa & 1 & 1015.496 & 1015.482 & 0.00138 & 14 \\
\hline \multicolumn{6}{|c|}{ Average mass error: } & 11 \\
\hline
\end{tabular}

The alphabetical designation (AD), amino acid sequence, and copy number (C\#) on the precursor are shown for each of the enterins. Enterins that were biochemically identified are shown in bold (see also Table 1). The letter on the left of each peptide denotes their alphabetical designation in order of first appearance on the precursor as ENa through ENt (e.g., VSPKYGHNFVamide is Enterin A or ENa, etc.). The predicted mass $\left([\mathrm{M}+\mathrm{H}]^{+}\right.$calculated $)$and average mass observed $\left(n=10,[\mathrm{M}+\mathrm{H}]^{+}\right.$observed) in MALDI-TOF MS is shown for each, along with the \% error in the measurement (also expressed as parts per million, ppm). Pyroglutamination of a number of enterins is based on MALDI-TOF analysis, not amino acid sequencing. 
GYSHSFVamide or KYGHNFVamide. We reasoned that if different enterins are coded by different mRNAs, it was likely that the most divergent of the enterins would be coded by different mRNAs. Thus, we designed our degenerate oligonucleotides on the basis of the primary structure of the two peptides that were the most divergent among those that were purified and sequenced. The two degenerate oligonucleotides were used in seminested RACE from $\lambda$ cDNA library to define the sequence upstream of these peptides. Library screening with probes generated in PCR reactions gave an overlapping set of clones, thus indicating that the two peptides were a product of the same precursor. Sequencing of the cDNA clones generated a 4092 bp consensus sequence (GenBank accession no. AY040526). Northern analysis (see Fig. 5) revealed that the mRNA is $\sim 4.2 \mathrm{~kb}$, thus suggesting that the consensus sequence is near full length.

The predicted mRNA contained a 2511 bp open reading frame that codes for a 837 amino acid precursor shown in Figure 2. The precursor had a predicted signal peptide and its predicted cleavage site was between Gly(25) and $\operatorname{Thr}(26)$ (Nielsen et al., 1997), indicating that the protein is targeted to the secretory pathway. Analysis of the precursor structure predicts that it codes for a total of 35 copies of 20 distinct but related amidated peptides as indicated by C-terminal glycines (Eipper et al., 1992) and furinlike consensus cleavage sites (Seidah and Chretien, 1999). The individual amidated peptides were named enterin A (ENa) through enterin $\mathrm{T}(\mathrm{ENt})$ in the order of first appearance on the precursor as shown in Table 2. In addition to the 20 enterins, the precursor predicts one amidated peptide that is structurally unrelated to the enterins, the amidated form of enterin connecting peptide (ECP)4 (ECP4-amide). The precursor also predicts at least 10 nonamidated linker or connecting peptides, most of which contain numerous acidic amino acids. Because in many precursors the acidic peptides are degraded, it has been postulated that they function to compensate for the basic nature of the processing sites. However, some connecting peptides are not degraded and indeed have been shown to be bioactive (Fan et al., 1997; Brezden et al., 1999).

Searches of GenBank with enterin precursor nucleotide and protein sequence failed to identify homologous genes in any species. However, this does not exclude the possibility that enterins or enterin-like peptides are expressed in other species because many neuropeptides, even in mammals, have yet to be identified. Additional work is necessary to determine how widespread the enterins and enterin-like peptides are in molluscs and other phyla.

\section{MALDI-TOF MS detection of enterins and connecting peptides in buccal neurons}

MALDI analysis was performed on the radula mechanoafferent sensory neuron (RM) cluster that was shown to be enterin positive by both immunostaining and in situ hybridization (see below). Neurons isolated from the caudal-dorsal sensory neuron cluster, which contains the RMs and other sensory neurons, were transferred to a MALDI sample plate for peptide analysis. The RMs were shown previously to contain the SCPs (Miller et al., 1994), whereas other neurons in caudal-dorsal sensory neuron cluster contain RFamides (Lloyd et al., 1987b; Ono and McCaman, 1992) and sensorin (Brunet et al., 1991). Sample preparation and mass spectrometric measurements were performed as described previously (Fujisawa et al., 1999). Because all of the enterins are within mass range from 950 to $1200 \mathrm{Da}$, high resolution and high accuracy mass measurement was needed to
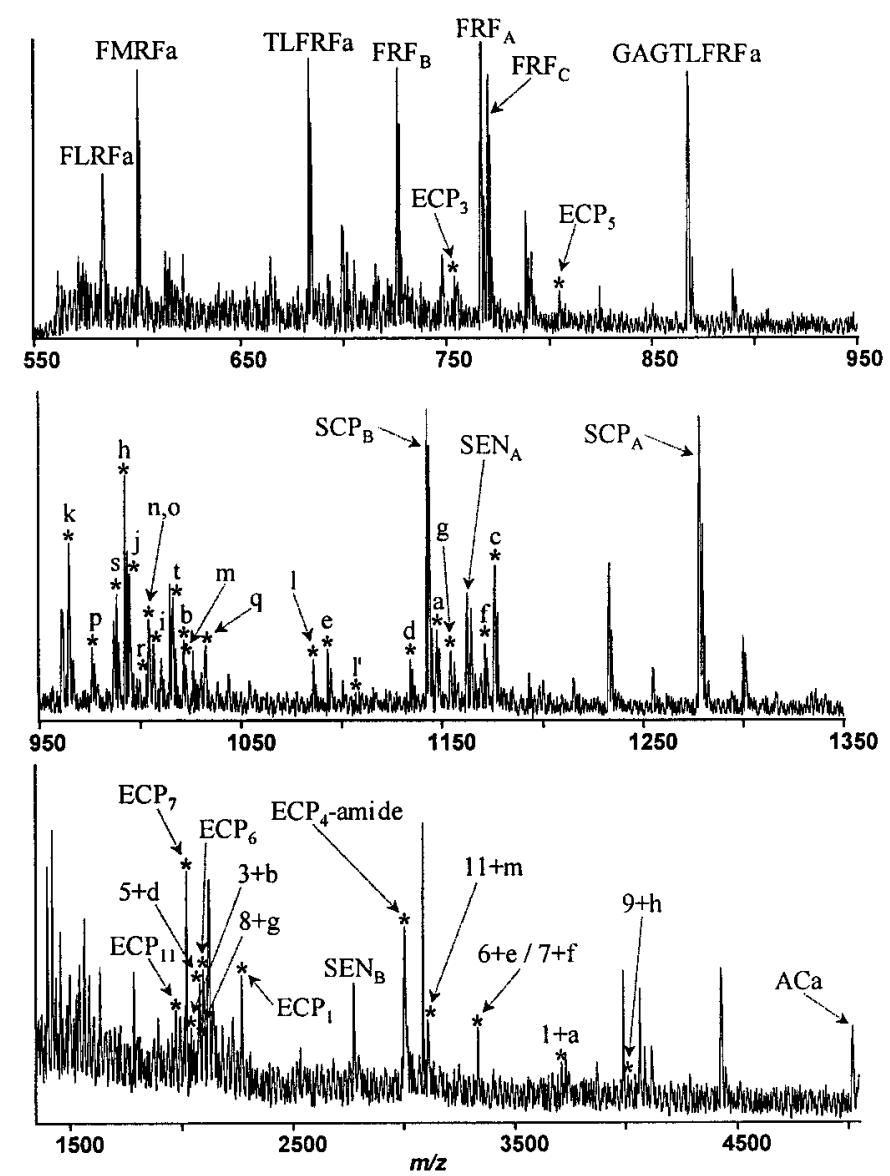

Figure 3. MALDI TOF mass spectrum (550-5000 Da range) from isolated buccal neurons of the rostral sensory cluster. Detection of the mass spectral peaks predicted by the putative amidated peptides on the enterin precursor confirm that they are in fact processed from the precursor. Assigned peaks are labeled with corresponding peptides. Peptides derived from five precursors, FMRFamide, FRFamide, SCP, sensorin, and enterin are also detected. Peaks corresponding to the products of the enterin precursor are shown with an asterisk. Lowercase letters signify the corresponding enterins, and numbers signify the corresponding enterinconnecting peptides $(E C P)$. Peaks labeled with a letter plus number correspond to amidated enterins still connected to their preceding ECP. Unamidated enterins were not detected. Enterins with a Gln at the N terminus (ENn, ENo, ENq, ENs, ENt) were detected only as a pyroglutamine form of the peptide. The enterin with a Glu at the $\mathrm{N}$ terminus (Enl) was detected as both $\mathrm{E}$ (labeled $l^{\prime}$ ) and $\mathrm{pE}$ (labeled $l$ ) forms of the peptide. Peaks with masses corresponding to all of the 20 fully processed enterins were detected. Two of the enterins, ENn and ENo, are isomers and could not be distinguished on the basis of molecular mass. In addition, some ECP and ECP-enterin peptides were detected. One of the ECPs, ECP4, was detected as an amidated form (ECP4-amide).

achieve correct peptide assignment. Therefore the reflectron mode was used, and mass calibration was optimized for the mass range of interest. Consistent with previous reports, we detected two forms of sensorin (Brunet et al., 1991), several RFamides (Schaefer et al., 1985; Cropper et al., 1994), and both forms of SCP (Mahon et al., 1985). FMRFamide [molecular weight (MW) 599.3] and $\mathrm{SCP}_{\mathrm{A}}$ (MW 1277.6) were used as internal calibrants to provide improved mass accuracy. Ten mass spectra were selected to calculate the average mass for each peak, and mass accuracy was calculated and given in both percentage error and parts per million format as shown in Table 2. The average mass measurement error is $11 \mathrm{ppm}$. More than 100 mass spectra of buccal neurons were obtained from 10 Aplysia. Figure 3 shows a repre- 


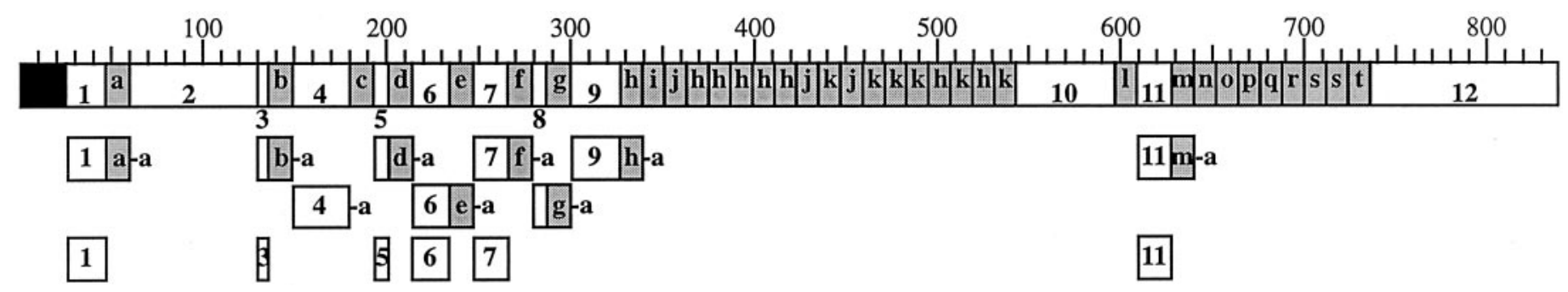

Figure 4. Summary of the enterin precursor structure and the enterin precursor-derived peptides. Schematic representation of the location of the enterins and enterin-connecting peptides on the precursor is shown with the amino acids numbered at the top. The black box represents the signal peptide, shaded boxes represent enterins, and white boxes represent ECPs. Lowercase letters identify corresponding enterins (ENa to ENt), and the numbers identify corresponding ECPs (ECP1 through ECP12). Although all of the enterins were detected by MALDI-TOF MS as fully processed peptides, this is not shown on the schematic for the sake of simplicity. Processed peptides, other than the enterins, that were detected by MALDI-TOF MS are shown on the schematic below their origin on the precursor. A lowercase $-a$ denotes that the amidated peptide was detected. Many enterins that were still connected to their preceding ECP were detected. Many of the ECPs were also detected, and ECP4 was detected as an amidated form.

sentative MALDI mass spectrum of buccal neurons containing enterin peptides. Each mass spectral peak is assigned on the basis of the experimentally observed molecular mass combined with enterin precursor sequence. From the enterin precursor, 20 different putative amidated peptides are predicted.

As shown in Figure 3, MALDI-MSs of a small population of buccal cells contain all of the 20 different enterins predicted by the enterin precursor. We cannot differentiate two enterins, QPSYGHSFVa (ENn) and QPGYSHSFVa (ENo), because they are isomers that contain the same amino acids and therefore have the same molecular weight. Interestingly, five peptides contain $\mathrm{N}$-terminal Gln, and one peptide has an N-terminal Glu. MALDI detects exclusively cyclized forms of Gln-derived pyroglutamate (pGlu; mass loss of $17.03 \mathrm{Da}$ ), and primarily pGlu form in the case of N-terminal Glu peptide (mass loss of $18.02 \mathrm{Da}$ ). pGlu formation is one of the most common post-translational modifications in peptides and is thought to be formed almost exclusively by intramolecular Gln cyclization (Busby et al., 1987; Fischer and Spiess, 1987). More recent studies have documented pGlu modification derived from N-terminal Glu (Bateman et al., 1990; Russo et al., 1997; Garden et al., 1999). In the case of N-terminal Glu, a small peak (Fig. 3, peak $l^{\prime}$ ) corresponding to the native form (MW 1103.56 Da) was also observed.

In addition to the amidated enterins, the enterin precursor predicts 12 ECPs. One of these ECPs, ECP4, has a C-terminal glycine and thus should be converted to ECP4-amide, a peptide that is structurally unrelated to the enterins. The predicted ECP4-amide was in fact observed by MALDI (Fig. 3). ECP4amide contains a number of basic residues, suggesting that this peptide may be further processed, but these fragments of ECP4amide were not detected by MALDI. In addition to ECP4-amide, a number of the other ECPs (ECP1, ECP3, ECP5, ECP6, ECP7, and ECP11) are also detected by MALDI. Peaks with masses corresponding to ECP2, ECP8, ECP9, ECP10, and ECP12 were not observed. The detection of ECP1 indicates that the correct signal peptide cleavage site was predicted from the enterin precursor amino acid sequence by SignalP (Nielsen et al., 1997). MALDI also detects some amidated enterins that are still attached to their $\mathrm{N}$-terminal ECP. These extended enterins are likely to represent intermediate processing products because the fully processed enterins are also detected. Some extended enterins are detected that contain an internal monobasic processing site (ECP5 + ENd, ECP6 + ENe, ECP7 + ENf, and ECP11 + $\mathrm{ENm})$, and some contain an internal dibasic processing site $(\mathrm{ECP} 1+\mathrm{ENa}, \mathrm{ECP} 3+\mathrm{ENb}, \mathrm{ECP} 8+\mathrm{ENg}$, and ECP9 + ENh).

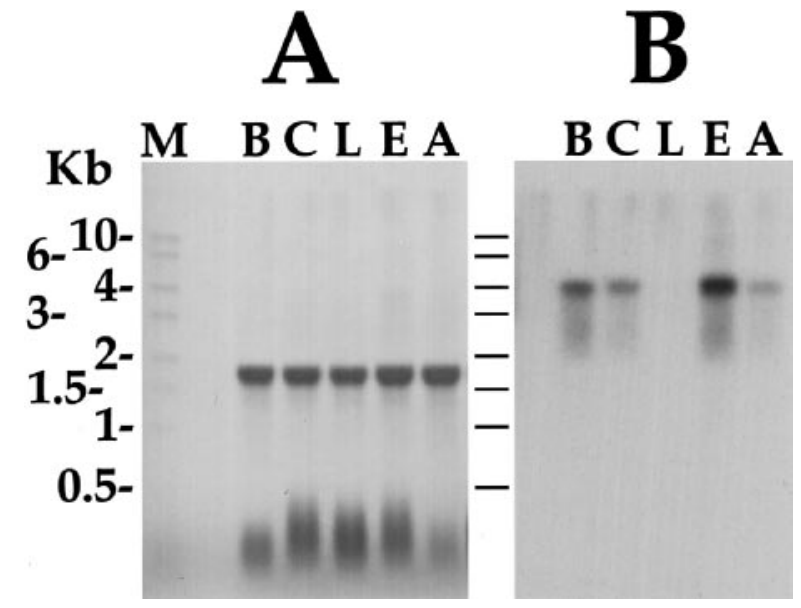

Figure 5. Northern blot of ganglionic distribution of enterin mRNA. $A$, Methylene blue-stained Northern blot of total RNA shows equal loading in all lanes. Aplysia ribosomal RNA runs as a single $18 \mathrm{sec}$ band. B, Hybridization of the same blot with an enterin coding sequence cDNA probe. $K b$, Kilobase; $M$, RNA size marker; $B$, buccal ganglion; $C$, cerebral ganglion; $L$, pleural ganglion; $E$, pedal ganglion; $A$, abdominal ganglion.

The structure of the enterin precursor and a summary of the peptides derived from the enterin precursor that were detected by MALDI are illustrated in Figure 4. Because all the enterins were detected by MALDI, the individual enterins derived from the enterin precursor are not illustrated in Figure 4 to simplify the figure.

Taken together, the simultaneous detection of all predicted amidated peptides and several linker peptides encoded by the enterin gene in small group of buccal cells confirms the gene expression in the Aplysia buccal ganglion. In addition, detection of multiple pGlu-modified forms of peptides containing N-terminal Gln and Glu provides evidence for additional posttranslational modification of the enterins.

\section{Distribution of enterins in the CNS and peripheral tissues}

Having identified the enterin gene and its peptide products we proceeded to characterize the localization of enterin containing neurons and their processes. Toward this goal we used a combination of molecular and immunological techniques.

The gross distribution of the enterin mRNA was determined using Northern analysis. This analysis was conducted on total 

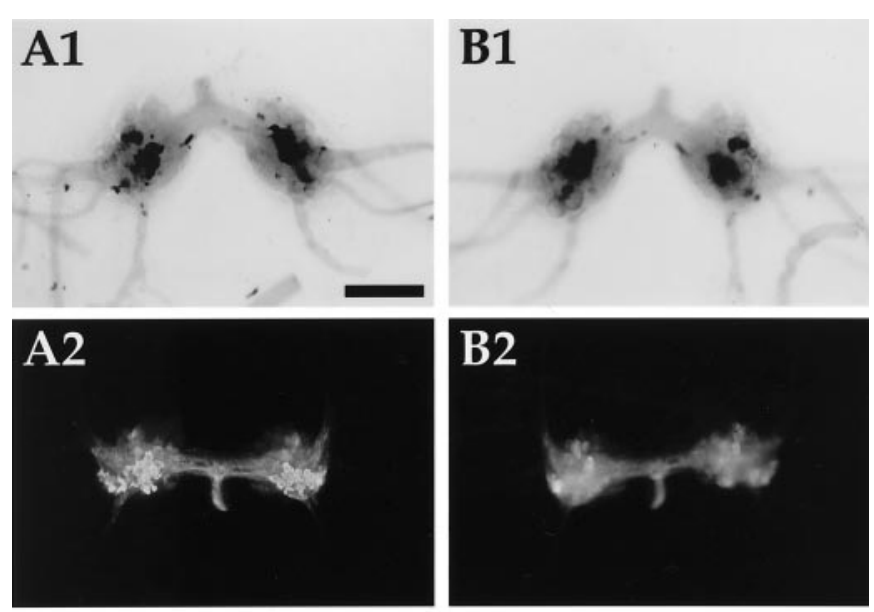

A3

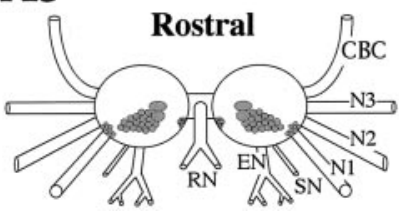

B3

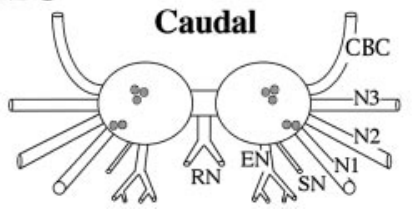

Figure 6. Enterin in the buccal ganglion. A1, In situ hybridization of rostral surface. $A 2$, Immunocytochemistry of rostral surface. Immunoreactive axons are present in the CBC. A3, Drawing of the enterin-positive neurons on the rostral surface of buccal ganglia. B1, In situ hybridization of caudal surface. B2, Immunocytochemistry of caudal surface. B3, Drawing of the enterin-positive neurons on the caudal surface of buccal ganglia. $C B C$, Cerebrobuccal connective; $N 1$, nerve 1 (B4); $N 2$, nerve 2 (B5); $N 3$, nerve 3 (B6); $S N$, salivary nerve (B3); $E N$, esophageal nerve (B2); $R N$, radula nerve (B1). Neurons drawn in darker shades of gray stain more intensely. Scale bar (shown in $A 1$ for all panels), $500 \mu \mathrm{m}$.

RNA obtained from specific ganglia of five animals. Northern analysis (Fig. 5) shows that enterin mRNA is unevenly distributed throughout the central ganglia of Aplysia and is $\sim 4.2 \mathrm{~kb}$ in length. The relative abundance of enterin mRNA in the CNS is pedal $>$ buccal $>$ cerebral $>$ abdominal $\gg$ pleural ganglia. More detailed information about the distribution of enterin-containing neurons and their processes was obtained using a combination of ISH and immunostaining. Correlation of immunostaining and ISH staining was used to assess the specificity of these two methods (Eberwine et al., 1994). The distribution of enterinpositive neurons (see below) was the same, independent of whether the cells were visualized with anti-enterin antibodies or with oligonucleotides designed on the basis of the enterin mRNA sequence, indicating that both staining methods are specific (Eberwine et al., 1994). Furthermore, on the more global level, enterin distribution observed using immunostaining and ISH staining was consistent with the distribution observed with Northern analysis. For instance, in Northern analysis (Fig. 5) the level of enterin mRNA in the pleural ganglia was below the level of detection, and only one or two neurons were detected in the pleural ganglia (see Fig. 10) using immunostaining and ISH staining. On the other hand, pedal ganglia contained a large cluster of enterin-staining neurons, and these ganglia produced a strong signal in Northern analysis.

For technical reasons, ISH staining was performed only on small animals (10-15 gm); however, both small and large animals were used for immunostaining. There was some variability in the number and size of neurons staining in different animals, even in the same weight range. What we present are typical results from both large and small animals. A diagram summarizing the distribution of enterin-positive neurons in each ganglion represents the correlated results of ISH staining and immunostaining. Locations of the nerves in the drawings are intended as landmarks; the relative positions of the neurons and nerves vary somewhat from animal to animal and depend on how the ganglia are pinned. To avoid redundancy, neurons that were observed to be both immunopositive and ISH positive are referred to as enterin positive. Because in situ hybridization cannot be used to define processes of neurons, cross-correlation is not possible. However, it is likely that immunostaining of processes reflects the presence of bona fide enterins because of the excellent cross-correlation of ISH staining and immunostaining of neuronal cell bodies.

\section{Buccal ganglion (Fig. 6)}

Both immunostaining and ISH staining revealed that practically all of the enterin-positive neurons were contained in a single cluster that was predominantly located in a region that extended from the central part of the rostral surface toward the dorsal edge of this surface. A cluster of smaller enterin-positive neurons was also observed in each hemiganglion near the buccal commissure. In contrast to the abundance of enterin-positive cells on the rostral surface, only four to five enterin-positive neurons were detected on the caudal surface. Two of these neurons were present in the ventral motoneuron cluster, and the remaining two to three neurons were localized to the dorsal edge in the area that was delineated by nerve 1 and the esophageal nerve. Immunostained axons were observed in all of the buccal nerves. The highest density of staining was observed in the radula nerve, a
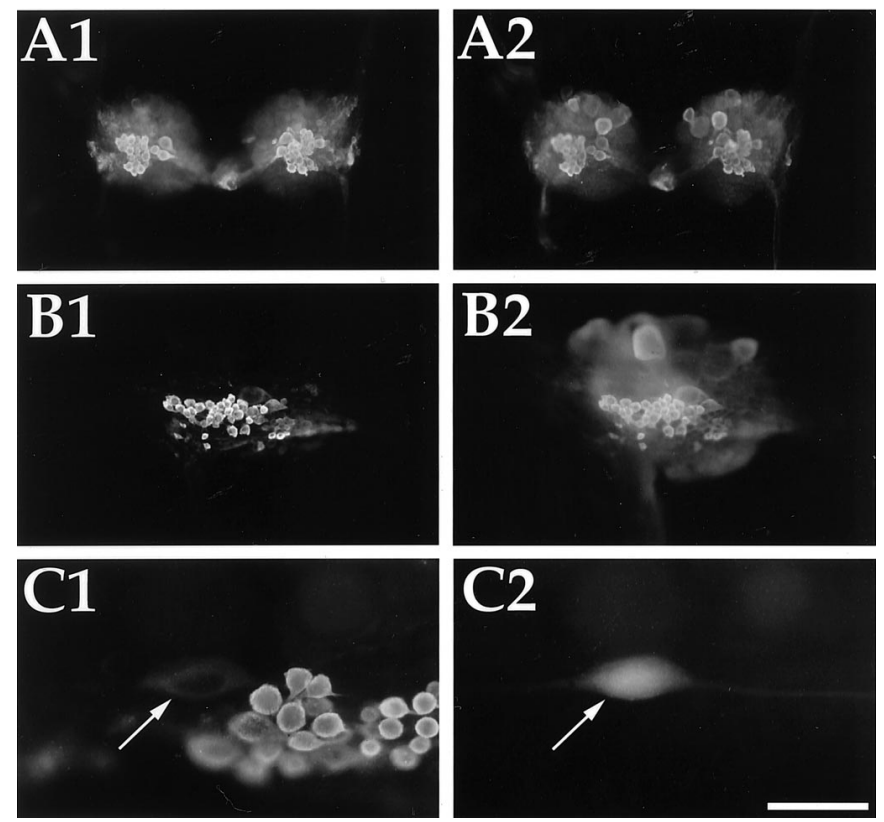

Figure 7. Enterin in the radula mechanoafferent sensory neurons of the buccal ganglion. $A$, A buccal ganglion from a juvenile Aplysia (10 gm) double labeled with rat antibody to enterin ( $A 1$, rhodamine red) and rabbit antibody to SCP ( $A 2$, fluorescein). $B$, A buccal hemiganglion from an adult Aplysia (200 gm). Enterin immunostaining (rhodamine red) is shown in B1, and SCP immunostaining (fluorescein) is shown in B2. C, A buccal hemiganglion from an adult animal immunostained with enterin (C1) in which B21 (arrows) was electrophysiologically identified and injected with carboxyfluorescein (C2). Scale bar (shown in $C 2$ ): $A, B, 500$ $\mu \mathrm{m} ; C, 100 \mu \mathrm{m}$. 

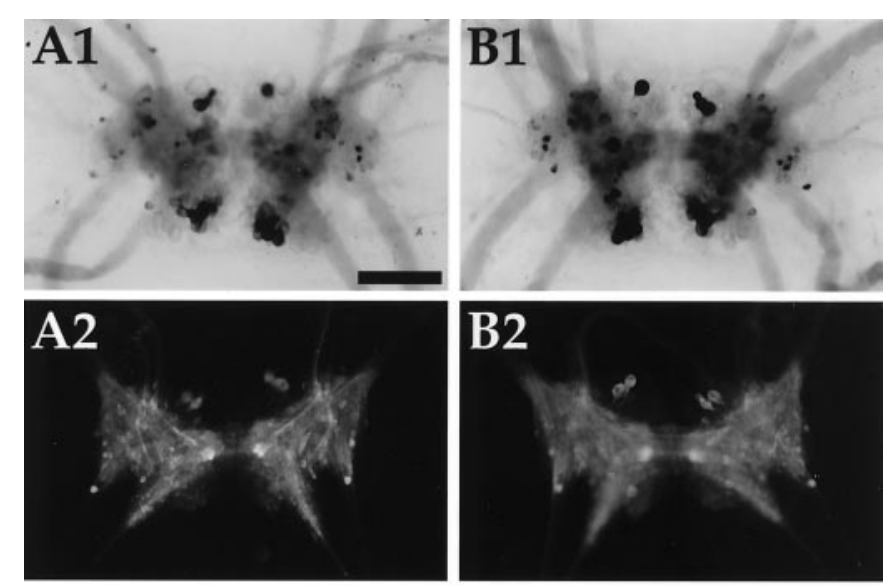

A3
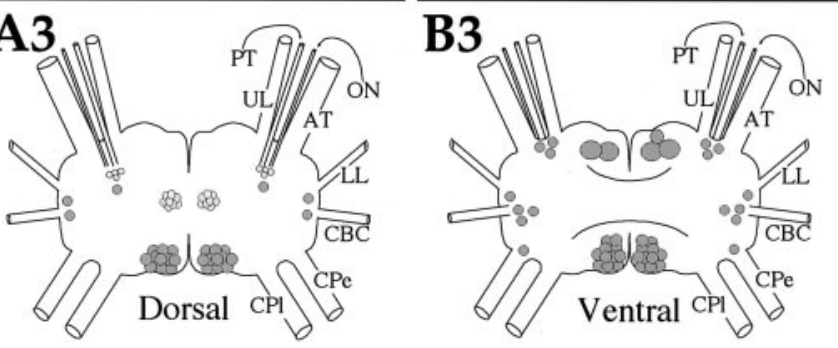

Figure 8. Enterin in the cerebral ganglion. A1, In situ hybridization of dorsal surface. $A 2$, Immunocytochemistry of dorsal surface. $A 3$, Drawing of the enterin neurons on the dorsal cerebral ganglion. B1, In situ hybridization of ventral surface. $B 2$, Immunocytochemistry of ventral surface. B3, Drawing of the enterin neurons on the ventral cerebral ganglion. $U L$, Upper labial nerve; $P T$, posterior tentacular nerve; $O N$, optic nerve; $A T$, anterior tentacular nerve; $L L$, lower labial nerve; $C B C$, cerebrobuccal connective; $\mathrm{Cpe}$, cerebropedal connective; $\mathrm{CPl}$, cerebropleural connective. Neurons drawn in darker shades of gray stain more intensely. Scale bar (shown in $A 1$ for all panels), $500 \mu \mathrm{m}$.

nerve through which radula mechanoafferents project (Miller et al., 1994). Interestingly, stained axons were also observed in the CBCs.

The localization of the rostral enterin-positive cluster of neurons appears to correspond to the previously described SCPpositive RM cluster (Miller et al., 1994). Neurons contained within that cluster were shown to innervate the subradula tissue and may be involved in the behavioral switch between bite and bite-swallow (Klein et al., 2000; Rosen et al., 2000). This cluster was originally identified as a subpopulation of buccal sensory neurons that immunostained for SCP. Here we show that all of the enterin-immunostained neurons (Fig. 7A1) in this cluster also immunostained for SCP (Fig. 7A2). Figure 7 also illustrates that the concordance of SCP and enterin staining is observed in both small (Fig. 7A) and large (Fig. 7B) animals. Because most electrophysiological studies of the RMs have been done using the largest identifiable neuron (B21) in this cluster, we sought to determine unequivocally whether this neuron is enterin positive. Figure $7 C 1$ shows enterin-immunopositive neurons, and Figure $7 C 2$ shows the carboxyfluorescein-injected neuron B21. Notice that the injected cell (arrow) is positive for enterins. The immunostaining of B21 is noticeably weaker than the staining of smaller neurons in the RM cluster. Related observations (data not shown) were made with in situ hybridization, which indicated that the largest neuron in the RM cluster showed weaker staining than the smaller cells.

\section{Cerebral ganglion (Fig. 8)}

The dorsal and ventral surfaces of the cerebral ganglia contained a comparable number of enterin-positive neurons. On the dorsal surface, a group of $\sim 20$ small cells in the F cluster were enterin positive [nomenclature of clusters according to Jahan-Parwar and Fredman (1976) and Phares and Lloyd (1996)]. Smaller numbers of cells were present in the E cluster and in the area in which optic nerves enter the cerebral ganglion. In the posterior part of the cerebral ganglion, enterin-positive cells were present in the B cluster. This cluster spans both the ventral and dorsal surfaces of the cerebral ganglion, and enterin-positive B cluster neurons were observed on both surfaces. This cluster of neurons exhibited
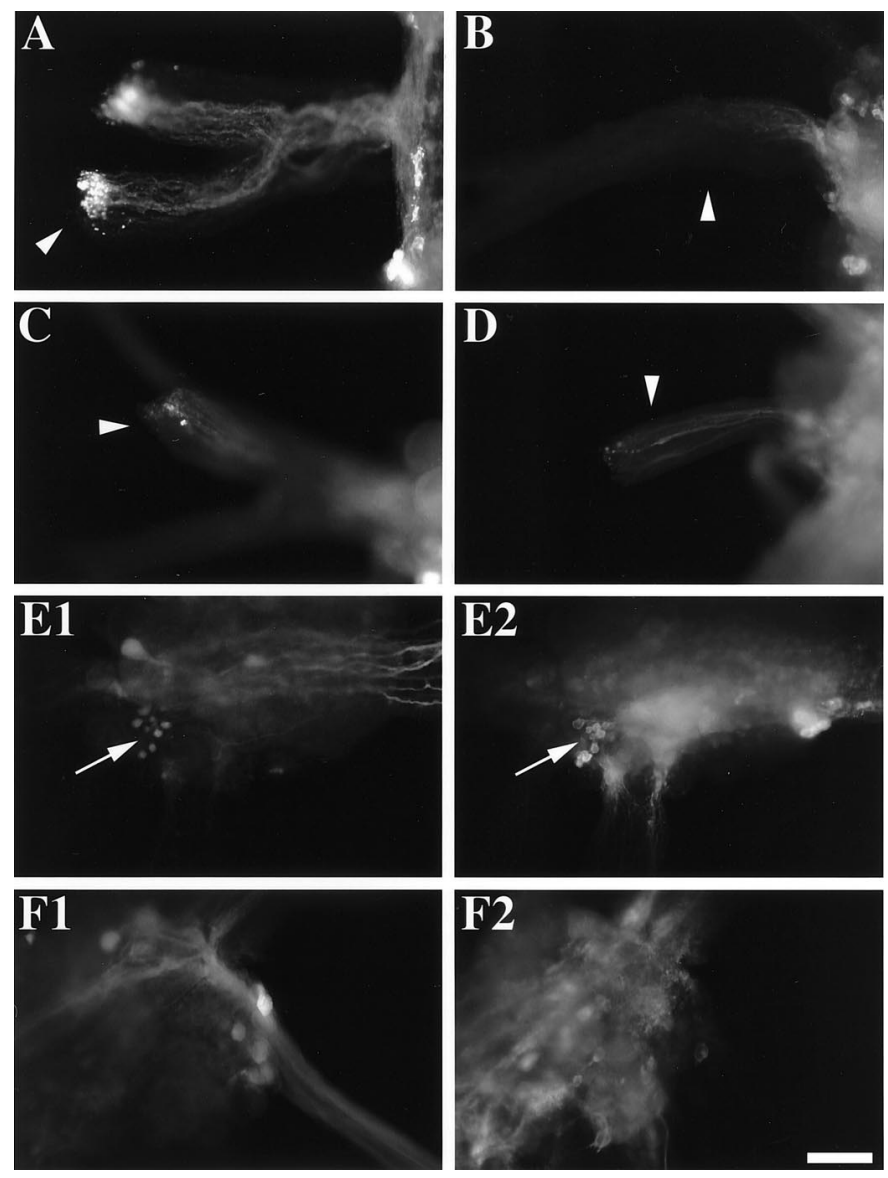

Figure 9. Enterin immunostaining in backfills of the CBC. A, Radula nerve (arrowhead) of the buccal ganglion (right) shows accumulation of enterin immunoreactivity, especially at the cut end. This suggests that the source of these axons is in the buccal ganglion. $B$, Esophageal nerve (arrowhead) of the buccal ganglion (right) shows depletion of enterin immunoreactivity from the cut end of the nerve (left). Some residual enterin immunoreactivity is observed in axons of this nerve nearer the buccal ganglion. $C, \mathrm{CBC}$ (arrowhead) on the side of the buccal ganglion (right) shows some accumulation of enterin immunoreactivity at the cut end of the nerve (left). D, CBC (arrowhead) on the side of the cerebral ganglion (right) also shows some accumulation of enterin immunoreactivity at the cut end of the nerve (left). E1, CBC backfill of the buccal ganglion (caudal surface of the contralateral hemiganglion) shows a cluster of a few small backfilled neurons (arrow) near the esophageal nerve and nerve 1. E2, Enterin immunostaining of the same field as in E1 shows that some of the backfilled neurons are enterin immunopositive (arrow). F1, CBC backfill of the cerebral ganglion (dorsal surface) shows several backfilled neurons in the ipsilateral E cluster. F2, Enterin immunostaining of the same field as in F1 shows that the backfilled neurons are not enterin immunopositive. Scale bar (shown in F2), $200 \mu \mathrm{m}$ for all panels. 
intense staining with ISH staining but displayed a weak immunostaining. Additional enterin-positive neurons on the ventral surface were observed in the $M$ cluster, the $E$ cluster, and the $G$ cluster.

To characterize the origin of the immunostained axons in the $\mathrm{CBC}$, we first examined accumulation versus depletion of enterins at the cut ends of nerves and then combined nerve backfills with imunostaining. To examine accumulation/depletion of enterins, tissue with its nerves cut was placed for $24 \mathrm{hr}$ in an organ culture. During this time, the enterins, like all other neuropeptides, continue to be transported in the nerves ( $\mathrm{Li}$ et al., 1998). If the neuronal somata that are the source of the enterin projections are proximal to the cut end of the nerve, the enterins will accumulate in the nerve, especially at the cut end. If the neuronal somata that are the source of the enterin projections are distal to the cut end of the nerve, the enterins will deplete in the nerve, especially from the cut end. This accumulation/depletion of enterins can be used to get information about the source of immunopositive axons in the $\mathrm{CBC}$ and other nerves. The use of collagenase in the incubation medium allowed for complete removal of the sheath covering the nerves and produced excellent immunostaining and visualization of enterin projections, both of which were critical for our analysis. For instance, the enterin-containing RMs in the buccal ganglion (see above) are known to project to the radula nerve (Miller et al., 1994). Thus, enterin should accumulate at the distal cut ends of the radula nerve of the buccal ganglion. This is in fact what we observe and is shown in Figure $9 A$. In contrast, the enterin-immunopositive material is depleted from the distal esophageal nerve of the buccal ganglion (Fig. $9 B$ ), although it is seen there in preparations that were fixed immediately after dissection (Fig. 6). This suggests that the neuronal somata that are the source of the enterin-immunopositive projections in the esophageal nerve are located outside the buccal ganglion, most likely in the gut (see below). In the $\mathrm{CBCs}$, accumulation of enterin-immunopositive material was observed at the distal cut ends of both the buccal (Fig. 9C) and cerebral (Fig. 9D) ganglia. This suggests that some of the enterin-immunopositive axons in

\section{Pleural and Pedal Ganglion}
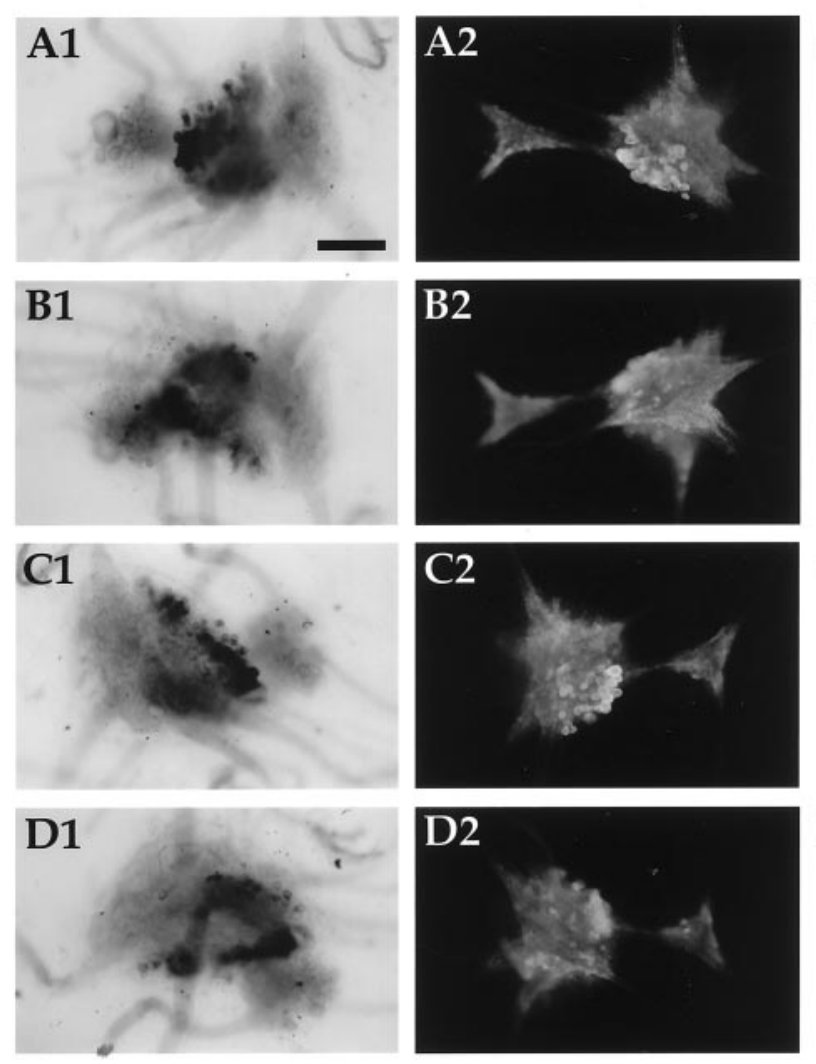

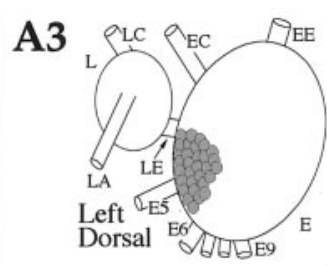

B3

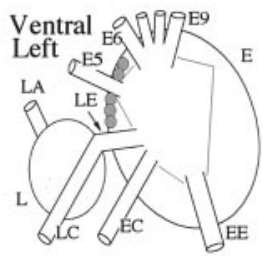

C3
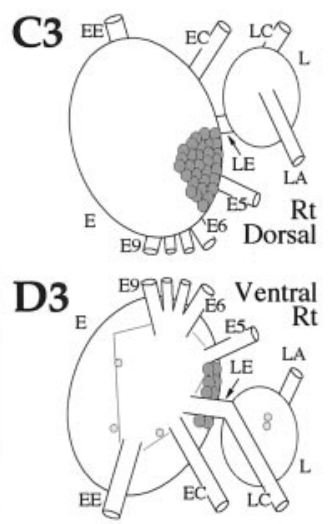

\section{Abdominal Ganglion}
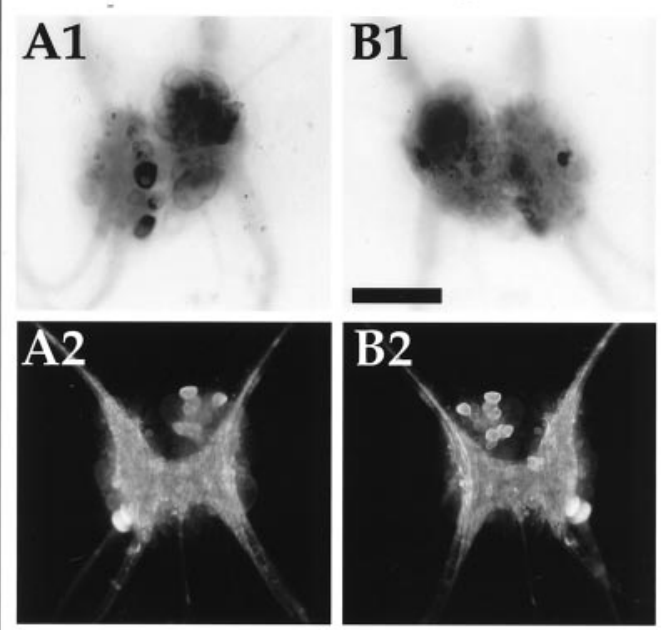

A3

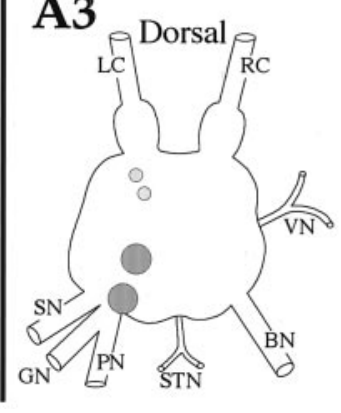

Figure 10. Enterin in the pleural, pedal, and abdominal ganglia. Pleural and Pedal Ganglion: A1, In situ hybridization of left ganglion pair dorsal surface. $A 2$, Immunocytochemistry of the left ganglion pair dorsal surface. $A 3$, Drawing of the enterin neurons on the dorsal surface of the left ganglion pair. B1, In situ hybridization of left ganglion pair ventral surface. B2, Immunocytochemistry of the left ganglion pair ventral surface. B3, Drawing of the enterin neurons on the ventral surface of the left ganglion pair. $C 1$, In situ hybridization of right ganglion pair dorsal surface. $C 2$, Immunocytochemistry of the right ganglion pair dorsal surface. C3, Drawing of the enterin neurons on the dorsal surface of the right ganglion pair. D1, In situ hybridization of right ganglion pair ventral surface. D2, Immunocytochemistry of the right ganglion pair ventral surface. D3, Drawing of the enterin neurons on the ventral surface of the right ganglion pair. $L$, Pleural ganglion; $E$, pedal ganglion; $L E$, pleuropedal connective; $E E$, pedal commissure; $E C$, cerebropedal connective; $L C$, cerebropleural connective; $L A$, pleuroabdominal connective; E5, posterior tegumentary nerve (P5); E6, anterior parapodial nerve (P6); E9, posterior pedal nerve (P9). Not all nerves are drawn for simplicity. Abdominal ganglion: A1, In situ hybridization of dorsal surface. A2, Immunocytochemistry of dorsal surface. $A 3$, Drawing of the enterin neurons on the dorsal abdominal ganglion. $B 1$, In situ hybridization of ventral surface. $B 2$, Immunocytochemistry of ventral surface. $B 3$, Drawing of the enterin neurons on the ventral abdominal ganglion. $L C$, Left pleuroabdominal connective; $R C$, right pleuroabdominal connective; $V N$, vulvar nerve; $B N$, branchial nerve; $S T N$, spermathecal nerve; $P N$, pericardial nerve; $G N$, genital nerve; $S N$, siphon nerve. Neurons drawn in darker shades of gray stain more intensely. Scale bars, $500 \mu \mathrm{m}$. 
the $\mathrm{CBC}$ are likely to originate from the buccal ganglion and some may originate in the cerebral ganglion.

To elucidate the location of the somata from which the enterinimmunopositive axons in the CBCs originate, we backfilled the $\mathrm{CBCs}$ in the direction of the cerebral and buccal ganglia and then immunostained these ganglia for enterin. We observed that there was a cluster of small enterin-immunopositive neurons on the caudal surface of the buccal ganglion that backfilled from the contralateral CBC (Fig. 9E) $(n=4)$. We also observed that there was a single enterin-immunopositive neuron in the dorsal $\mathrm{E}$ cluster of the cerebral ganglion, but that neuron did not backfill from the ipsilateral CBC (Fig. $9 F)(n=4)$. The backfilled neurons in the $\mathrm{M}$ cluster of the ventral cerebral ganglion also lacked enterin immunostaining (data not shown). Thus the source of the enterin in the $\mathrm{CBC}$ on the cerebral side remains unclear and may originate in neurons outside the cerebral ganglion. The localization of enterin to neurons that are likely to participate in the generation of feeding behavior suggests that enterin may possess some physiological actions on the feeding circuitry.

\section{Pleural, pedal, and abdominal ganglia (Fig. 10)}

Only one or two enterin-positive neurons were observed in pleural ganglia. These neurons are not located in the superficial layer of cells. In the pedal ganglia, most of the neurons were localized to a cluster of neurons that extends from the dorsal to the ventral surface in the vicinity of the pleural-pedal connective. Occasional additional cells were observed in other parts of the pedal ganglia. In the abdominal ganglia two large enterin-positive neurons were observed in the lower left quadrant. Two smaller enterin-positive cells were seen in the upper left quadrant below the bag cell cluster. A major cluster of enterin-positive cells was observed in the upper right quadrant of the abdominal ganglion. These cells are covered by other neurons on both surfaces of the ganglia. We arbitrarily decided to draw them on the ventral surface of the schematic localization of neurons. On the left side of the ventral surface of the abdominal ganglion, one very lateral and one medial enterin-positive neuron were observed.

\section{Digestive system (Fig. 11)}

Because a number of the enterins were purified from the gut, we investigated the distribution of enterins within various parts of the digestive system. The digestive tract of Aplysia consists of the esophagus, the crop, the triturating stomach (anterior gizzard), the filter chamber (posterior gizzard), the intestine (true stomach), and the rectum (Kandel, 1979; Lloyd et al., 1988). Enterinpositive neuronal somata were observed with both ISH staining and immunostaining in the esophagus and crop (Fig. 11A-D). These parts of the digestive system also contained numerous enterin-immunopositive neural processes, some of which could be easily traced to specific neurons. Dense enterin-immunostained processes were observed in the stomatogastric ring (Fujisawa et al., 1999) (Fig. 11E), but only sparse immunostained processes were observed in the triturating stomach and the filter chamber (Fig. $11 F$ ). Enterin immunostaining appeared to be confined to neuronal-type cell bodies and processes. No enterin-immunostained neuronal somata were detected in the stomatogastric ring, the triturating stomach, or the filter chamber.

\section{Physiological action of enterins \\ Digestive tract}

Because the enterins were purified from the gut of the animal on the basis of their bioactivity, it was important to confirm that the bioactivity observed during purification was indeed caused by the enterins. Furthermore, because the sequences of enterins are diverse, one of the immediate questions is their relative potency in physiological actions. To address this issue, we compared the inhibitory actions of several enterins on contractions of the gut. Figure $12 A$ shows a typical example obtained in the isolated triturating stomach. Spontaneous contractions of the triturating stomach were inhibited in a concentration-dependent manner by ENh. In Figure 12B, dose-response relationships of six enterins are illustrated. Threshold concentrations of the enterins were $10^{-10} \mathrm{M}$ or less, and in many cases $10^{-7} \mathrm{M}$ almost abolished spontaneous contractions. The effects of enterins reversed com-
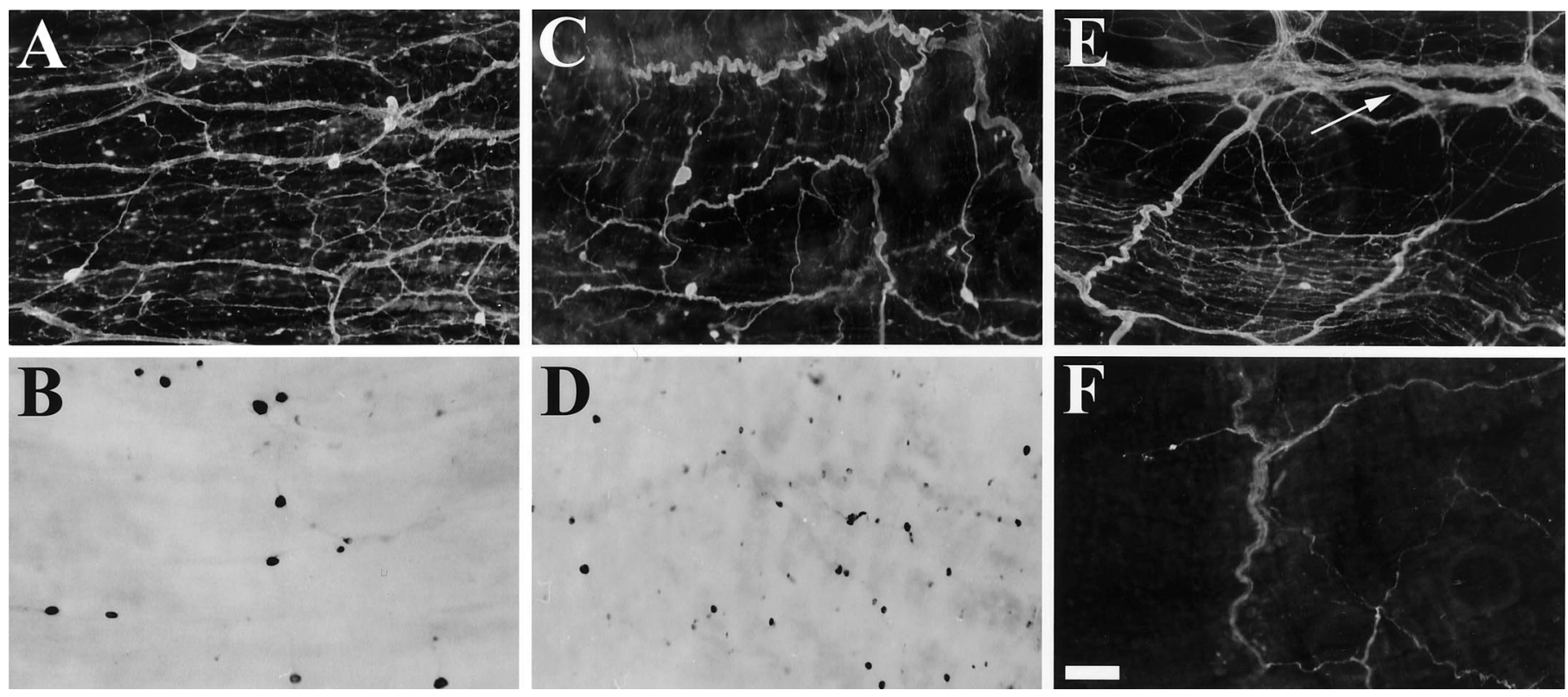

Figure 11. Enterin in the digestive tract. $A$, Esophagus immunostaining. $B$, Esophagus in situ hybridization. $C$, Crop immunostaining. $D$, Crop in situ hybridization. E, Stomatogastric ring (arrow) immunostaining. The crop is below and triturating stomach is above the arrow. $F$, Filter chamber immunostaining. All panels are from 10-15 gm Aplysia. Scale bar (shown in F), $200 \mu \mathrm{m}$ for all panels. 
A
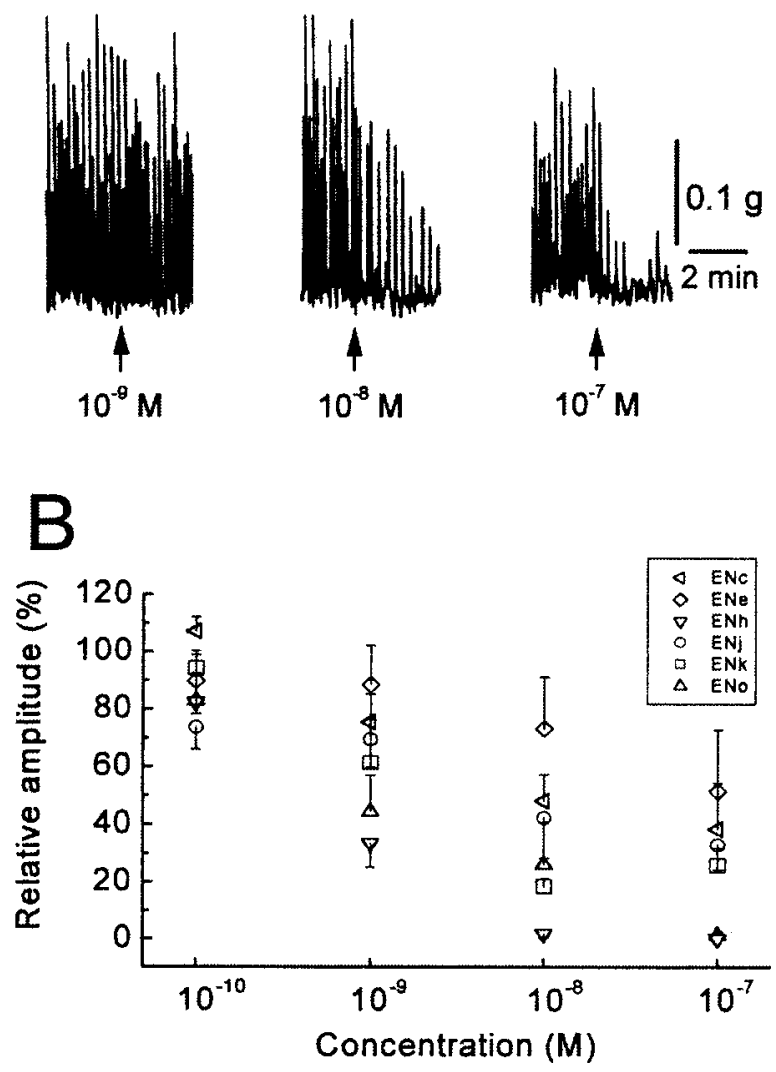

Figure 12. Inhibitory actions of enterins on the Aplysia triturating stomach. $A$, Effects of ENh on spontaneous contractions of the triturating stomach. $B$, Concentration-response relationships of six enterins. Each symbol shows a mean of three to four preparations, and upward or downward bar indicates SE of the mean. The potency of four nonapeptides that have a consensus sequence of XPGYSHSFVamide appeared to be almost identical. One-way ANOVA showed that there was no statistically significant difference between the enterins tested except at $10^{-7} \mathrm{M}$ $\left(10^{-10} \mathrm{M}, F_{(3,12)}=1.50, p>0.26 ; 10^{-9} \mathrm{M}, F_{(3,12)}=1.91, p>0.18 ; 10^{-8}\right.$ $\left.\mathrm{M}, F_{(3,12)}=2.69, p>0.09 ; 10^{-7} \mathrm{M}, F_{(3,12)}=10.00, p<0.002\right)$. At $10^{-7}$ $\mathrm{M}$, ENo and ENh seemed to be more potent than ENk or ENj (TukeyKramer test; $p<0.05)$. Two tested decapeptides, ENc and ENe, may be slightly less than the nonapeptides. If the results of the two decapeptides are included in the analysis, there is a statistically significant difference in their potency $\left(10^{-10} \mathrm{M}, F_{(5,17)}=2.81, p<0.05 ; 10^{-9} \mathrm{M}, F_{(5,17)}=2.88\right.$, $\left.p<0.05 ; 10^{-8} \mathrm{M}, F_{(5,17)}=4.74, p<0.01 ; 10^{-7} \mathrm{M}, F_{(5,17)}=3.73, p<0.05\right)$. At these concentrations, ENe was less potent than ENh (Tukey-Kramer test; $p<0.01$ at $10^{-8} \mathrm{M}, p<0.05$ at $\left.10^{-7} \mathrm{M}\right)$.

pletely after a 15 min washout, except at the highest dosage. After application of the highest dosage, the experiment was terminated. There were only minor differences in the potencies of the enterins tested (see legend for Fig. 12). The enterins inhibited the esophagus with a similar concentration-response relationship (data not shown). We also tested another decapeptide, ENa, in this tissue. There was no statistical significance, however, among the different potencies of seven tested enterins in the esophagus except at $10^{-9} \mathrm{M}\left(F_{(6,20)}=3.23 ; p<0.05\right)$, where ENc was less potent than ENh (Tukey-Kramer test; $p<0.05$ ). Thus, the enterins that we tested seem to be functionally redundant in the digestive tract, although there were some exceptions, and we did not examine all of the enterins. Of course, our results do not rule out a possibility that a different rank order of enterins exists in other targets.

\section{CNS}

Because the enterins were localized to neurons that are likely to participate in the generation of feeding behavior, we sought to determine whether the enterins are also bioactive on the feeding circuitry. We examined the effects of enterins on feeding motor programs induced by the command-like neuron, cerebral buccal interneuron 2 (CBI-2) (Rosen et al., 1991). Because the different forms of enterins appeared to be functionally redundant in their effects on gut contractions, we tested only one of the enterins (ENk) on the feeding circuitry. Enterin did not seem to have any significant effect on the duration of either the protraction or retraction phase of CBI-2-elicited programs. However, the multifunctional and practically identical neurons B4/5 fired fewer action potentials when enterin was present $(n=7)$. This was associated with an increase in firing of B8 (Fig. 13), a neuron that is monosynaptically inhibited by B4/5. Therefore, we sought to determine whether enterin had any effect on the excitability of $\mathrm{B} 4 / 5$. Because of their large size, B4/5 was impaled with two electrodes, one of which was used for voltage recording and one for current injections. A $3 \mathrm{sec}$ depolarizing pulse was applied into B4/5 through the current electrode every half minute. The amplitude of the current was adjusted at the beginning of the experiment so that the firing frequency of B4/5 was $\sim 8 \mathrm{~Hz}(\sim 25$ spikes in $3 \mathrm{sec})$. Enterin was applied in concentrations that increased from $10^{-7}$ to $10^{-5} \mathrm{M}$. Enterin reversibly reduced the firing rate of B4/5 in a concentration-dependent manner (Fig. 14) $(n=4)$. Group data are shown in Figure 14B. An overall statistically significant difference between the different conditions was observed (ANOVA, repeated measures; $F_{(3,9)}=66.26 ; p<$ $0.0001)$. When individual comparisons were made between different peptide concentrations and control (means of beforepeptide application and after-peptide wash), we found a statistically significant decrease of B4/5 excitability at $10^{-6}$ and $10^{-5} \mathrm{M}$ enterin (Bonferroni multiple comparisons test; $p<0.001$ for $10^{-6} \mathrm{M}$ enterin and $p<0.001$ for $10^{-5} \mathrm{M}$ enterin). No obvious effect on the resting potential of B4/5 was observed. Because experiments on the excitability of $\mathrm{B} 4 / 5$ were performed in normal ASW, we cannot exclude the possibility that the effects of enterin were polysynaptically mediated.

\section{DISCUSSION}

In this study, we sought to identify neuropeptides that exert widespread actions by identifying peptides that are present in both the CNS and the gut of Aplysia. We purified three decapeptides and seven nonapeptides from extracts of the digestive tract and CNS of $A$. kurodai. The structure of the precursor that encodes these peptides was deduced from cDNA cloning, and the precursor was found to predict 35 copies of 20 different structurally related peptides. We named these peptides enterins because they were purified from the gut and are localized in the enteric nervous system. Because enterins are structurally related and derived from the same precursor, they constitute a single peptide family.

The structural similarities between enterins are apparent, especially at the $\mathrm{C}$ terminus. Of the predicted copies, 19 of 35 are nonapeptides with a sequence of XPGYSHSFVamide. Except for ENc and ENm, the C-terminal sequence of all other enterins is HXFVamide. Despite such conservation, a significant diversity of amino acid sequence exists within the enterin family. Even the most abundant form in the precursor $(\mathrm{ENh})$ represents just 8 of 35 copies of the enterins. Such structural diversity between single 

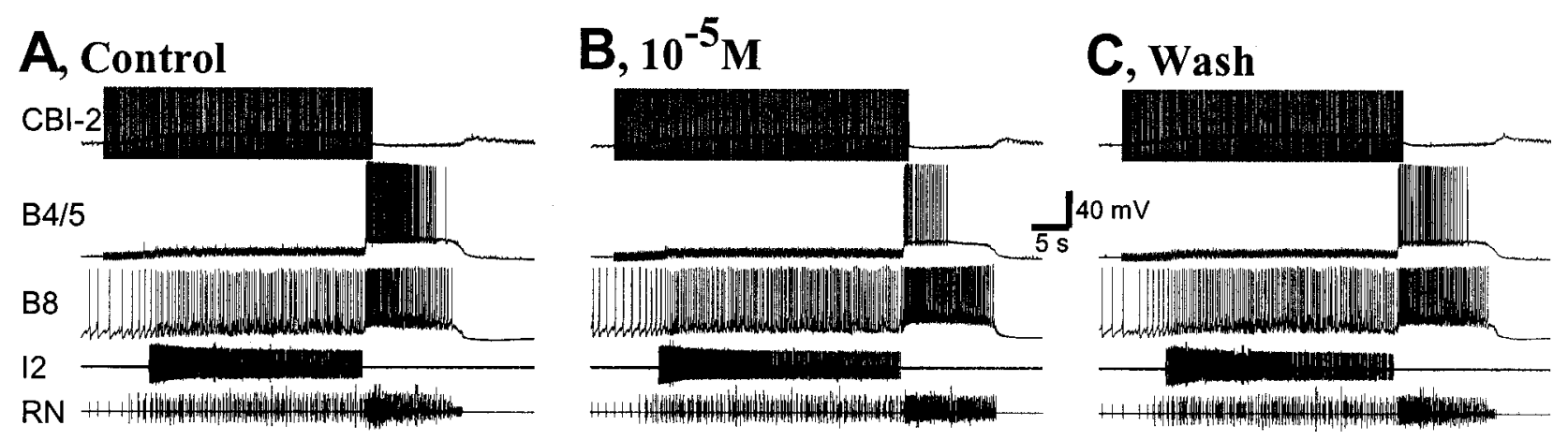

Figure 13. Enterin reduces spike activity of multifunctional neurons B4/5 during feeding motor program elicited by CBI-2. Single cycles of feeding motor programs, comprising a protraction-retraction sequence, were elicited every 2 min by CBI-2 stimulation at $9 \mathrm{~Hz}$. CBI- 2 stimulation was terminated after the end of the protraction phase. Protraction phase was monitored by activity in the I2 nerve (I2). Retraction phase was monitored by sustained depolarization in B4/5 that occurs after termination of 12 nerve activity. The activity of radula closing motor neuron B8, also shown in radula nerve $(R N)$, occurred during the retraction phase. This suggests that the motor program was ingestive. Superfusion of $10 \mu \mathrm{M}$ ENk had no significant effect on the duration of protraction and retraction but reduced the B4/5 firing rate (Control $=77$ spikes; $10^{-5} M=24$ spikes; Wash $=46$ spikes).
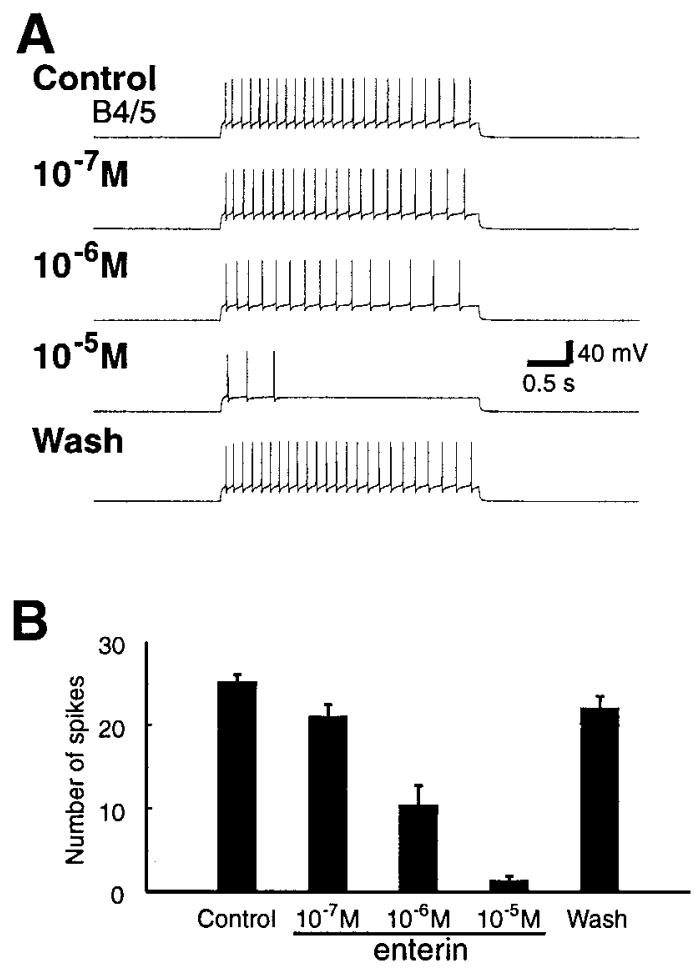

Figure 14. Enterin reduces the excitability of the multifunctional neurons $\mathrm{B} 4 / 5$. $A$, Sample recording from $\mathrm{B} 4 / 5$. A $3 \mathrm{sec}$ depolarizing pulse was applied to induce regular firing of B $4 / 5$ at $\sim 8 \mathrm{~Hz}$ every half minute. The B4/5 firing was reduced when ENk was applied, and the ENk-induced reduction of B4/5 firing was concentration-dependent. $B$, Group data (mean \pm SEM; $n=4$ ) showing the inhibitory effects of ENk on B4/5 excitability.

precursor derived peptides has been observed in Aplysia (Miller et al., 1993a,b; Fujisawa et al., 1999).

Because only 10 of the 20 unique enterins were biochemically isolated, we sought to confirm the expression of the remaining 10 forms. We used MALDI-TOF MS, a technique that allows detection of very small amounts of neuropeptides. MALDI-TOF MS is particularly powerful when it is combined with sequence information derived from biochemical and molecular studies (Jimenez et al., 1994; Li et al., 1998; Worster et al., 1998; Floyd et al., 1999). With MALDI-TOF MS we did in fact observe mass spectral peaks corresponding to all of the predicted enterins in a sample prepared from a cluster of buccal neurons that was shown to contain enterin-positive neurons using immunocytochemistry and ISH.

A number of enterins contain an N-terminal glutamine or glutamate, both of which are potential targets for pyroglutamination (Busby et al., 1987; Fischer and Spiess, 1987; Bateman et al., 1990; Russo et al., 1997; Garden et al., 1999). MALDI-TOF MS analysis confirmed that this is the case. In fact, only ENl is observed in both the pGlu and the non-pGlu forms. The detection of $N$-pyroglutamyl peptides is not considered to be an artifact of MALDI (Garden et al., 1999). The result suggests that $N$-pyroglutamyl enterins may be important for the functions of these buccal mechanoafferent cells. Interestingly, in A. kurodai, enterins with unmodified glutamate and glutamine were isolated, suggesting that either the processing kinetics of pyroglutamination is slower in this animal or that pyroglutamination may be cell or tissue specific.

A number of putative basic processing sites predict that in addition to the enterins the precursor may give rise to 12 additional peptides. We observed peaks in the mass spectra that correspond to 6 of the 12 predicted peptides. It should be noted that some of the observed peptides may represent processing intermediates because enterins still attached to ECPs were observed. Most of the ECPs are highly acidic and may be ultimately degraded. Such acidic peptides or their amino acid residues are thought to function to create an acidic intravesicular environment (Scheller and Kirk, 1987). However, because one of these peptides, ECP4, is observed as an amidated product and amidation is a common characteristic of bioactive peptides, it is possible that ECP4-amide is bioactive.

Because the CNS and the gut are connected via the esophageal nerve and enterins were isolated from both CNS and gut, we sought to localize the enterins in both structures. Using a combination of immunostaining and ISH, we demonstrated that enterin-containing somata were present in both the CNS and the gut. A particularly dense innervation was observed in the esophagus and crop. Esophageal contractions have to be accurately coordinated with contraction of the buccal mass. Interestingly, enterin-stained axons were present in the esophageal nerve, suggesting that enterin may play a role in communication between the gut and the CNS that controls contractions of the buccal mass. In preparations that were fixed after the esophageal nerve was 
cut, enterin-immunopositive material was depleted from the esophageal nerve that was attached to the buccal ganglion. This depletion suggests that the enterin-positive neurons that project to the esophageal nerve reside in the gut. Thus, enterin-positive neurons in the gut may project to the buccal ganglion and influence the output of the CPG that controls the buccal mass.

In the periphery, various enterins were found to powerfully inhibit contractions of the esophagus and triturating stomach. Distinct peptides from the same precursor may have different physiological potency (Cropper et al., 1991; Vilim et al., 1994; Fujisawa et al., 1999) or may be functionally redundant (Hewes et al., 1998). Inhibitory actions of selected enterins that we examined were not statistically different from each other. Thus, at least some of the diverse enterins appear to be functionally redundant in this tissue. Because we have not yet tested all forms of enterins and a potency order of structurally related peptides can be different among different targets even in the same species (Fujisawa et al., 1999), more thorough systematic pharmacological studies are required to unequivocally address the issue of functional redundancy.

Within the part of the CNS that participates in consummatory feeding, we detected enterins in both the cerebral and buccal ganglia. Interestingly, enterin-like immunoreactivity was also detected within the cerebral-buccal connective. In preparations that were fixed after the CBCs were cut, we observed accumulation of enterins in some fibers on both ends of the CBC. This suggests the presence of a two-way enterin projection system within the CBC. Backfills from the CBCs combined with immunocytochemistry demonstrated that enterin was present in one of the CBCs and in a subpopulation of buccal-cerebral interneurons contralateral to the backfilled $\mathrm{CBCs}$ in the buccal ganglia. Because the enterins were present in both ganglia that control consummatory feeding and in the nerve that connects the two, we examined the effects of enterins on feeding motor patterns. We found that when feeding motor patterns were evoked by stimulation of the command-like neuron CBI-2, the overall phasing of the pattern was not affected. However, we observed a reduction of the firing of the mixed function neurons B4/5 that are active during the retraction phase. Direct measurements of B4/5 excitability indicated that the enterins act to reduce the excitability of B4/5. The B4/5 neurons have been shown to be more active in egestive than in ingestive behaviors (Warman and Chiel, 1995), and it has been suggested that suppression of B4/5 activity may play an important role in determining whether the feeding network generates ingestive or egestive motor programs (Kabotyanski et al., 1998; Jing and Weiss, 2001). We have not identified the neural source of the enterin-mediated inhibition of B4/5. However, enterin staining demonstrated the presence of previously unidentified clusters of neurons. Thus enterin staining can be used to identify this new population of neurons and to study their physiological functions.

Enterins were present not only in cerebral and buccal ganglia (which participate in ingestion and egestion) but were also detected in both the somata and neuropile of all other ganglia. Enterin was most prevalent in the pedal ganglia. On the basis of the large size of the majority of the enterin-positive pedalganglia neurons and the presence of enterin in peripheral nerves, this group of neurons may represent motoneurons. No information is available about the scattered small pedal neurons. Because sensory neurons in Aplysia tend to form clusters, the small pedal cells are probably not sensory neurons. A few scattered small cells were observed in the pleural ganglia, and their location makes them unlikely to be part of the identified pleural sensory clusters.
In the abdominal ganglia, we observed two large neurons in the lower left quadrant. A cluster of nonsuperficial neurons was observed in the upper right quadrant of the abdominal ganglia. Finally, we also observed some scattered small neurons within this ganglion. The presence of enterin in all of the ganglia, which are involved in distinct behaviors of the animal (Kandel, 1979), indicates that actions of enterins may not be limited to feeding and that this family of peptides may have a broad spectrum of actions.

In summary, on the basis of the idea that some neuropeptides are part of the brain-gut axis (Gue and Bueno, 1996) that may regulate both the central and visceral aspects of feeding behaviors, we sought to identify peptides present in both loci. We used a combination of biochemical and molecular techniques to identify and map the expression of a new family of such peptides, the enterins. Using physiological techniques, we demonstrated that enterins are active in both the CNS and the gut. Furthermore, we demonstrated that these peptides are present throughout the nervous system and therefore may also play a regulatory role in nonfeeding behaviors of Aplysia.

\section{REFERENCES}

Bateman A, Solomon S, Bennett HP (1990) Post-translational modification of bovine pro-opiomelanocortin. Tyrosine sulfation and pyroglutamate formation, a mass spectrometric study. J Biol Chem 265:22130-22136.

Brezden BL, Yeoman MS, Gardner DR, Benjamin PR (1999) FMRFamide-activated Ca2 + channels in Lymnaea heart cells are modulated by "SEEPLY," a neuropeptide encoded on the same gene. J Neurophysiol 81:1818-1826.

Brezina V, Weiss KR (1997) Analyzing the functional consequences of transmitter complexity. Trends Neurosci 20:538-543.

Brunet JF, Shapiro E, Foster SA, Kandel ER, Iino Y (1991) Identification of a peptide specific for Aplysia sensory neurons by PCR-based differential screening. Science 252:856-859.

Busby WH, Quackenbush GE, Humm J, Youngblood WW, Kizer JS (1987) An enzyme(s) that converts glutaminyl-peptides into pyroglutamyl-peptides. Presence in pituitary, brain, adrenal medulla, and lymphocytes. J Biol Chem 262:8532-8536.

Chomczynski P, Sacchi N (1987) Single-step method of RNA isolation by acid guanidinium thiocyanate-phenol-chloroform extraction. Anal Biochem 162:156-159.

Cropper EC, Tenenbaum R, Kolks MA, Kupfermann I, Weiss KR (1987) Myomodulin: a bioactive neuropeptide present in an identified cholinergic buccal motor neuron of Aplysia. Proc Natl Acad Sci USA 84:5483-5486.

Cropper EC, Vilim FS, Alevizos A, Tenenbaum R, Kolks MA, Rosen S, Kupfermann I, Weiss KR (1991) Structure, bioactivity, and cellular localization of myomodulin B: a novel Aplysia peptide. Peptides 12:683-690.

Cropper EC, Brezina V, Vilim FS, Harish O, Price DA, Rosen S, Kupfermann I, Weiss KR (1994) FRF peptides in the ARC neuromuscular system of Aplysia: purification and physiological actions. J Neurophysiol 72:2181-2195.

Cruz LJ, de Santos V, Zafaralla GC, Ramilo CA, Zeikus R, Gray WR, Olivera BM (1987) Invertebrate vasopressin/oxytocin homologs Characterization of peptides from Conus geographus and Conus straitus venoms. J Biol Chem 262:15821-15824.

Eberwine JH, Valentino KL, Barchas JD (1994) In situ hybridization in neurobiology: advances in methodology. New York: Oxford UP.

Eipper BA, Stoffers DA, Mains RE (1992) The biosynthesis of neuropeptides: peptide alpha-amidation. Annu Rev Neurosci 15:57-85.

Fan X, Croll RP, Wu B, Fang L, Shen Q, Painter SD, Nagle GT (1997) Molecular cloning of a cDNA encoding the neuropeptides APGWamide and cerebral peptide 1: localization of APGWamide-like immunoreactivity in the central nervous system and male reproductive organs of Aplysia. J Comp Neurol 387:53-62.

Fischer WH, Spiess J (1987) Identification of a mammalian glutaminyl cyclase converting glutaminyl into pyroglutamyl peptides. Proc Natl Acad Sci USA 84:3628-3632.

Floyd PD, Li L, Rubakhin SS, Sweedler JV, Horn CC, Kupfermann I, Alexeeva VY, Ellis TA, Dembrow NC, Weiss KR, Vilim FS (1999) Insulin prohormone processing, distribution, and relation to metabolism in Aplysia californica. J Neurosci 19:7732-7741.

Fujisawa Y, Furukawa Y, Ohta S, Ellis TA, Dembrow NC, Li L, Floyd PD, Sweedler JV, Minakata H, Nakamaru K, Morishita F, Matsushima O, Weiss KR, Vilim FS (1999) The Aplysia mytilus inhibitory peptide- 
related peptides: identification, cloning, processing, distribution, and action. J Neurosci 19:9618-9634.

Garden RW, Moroz TP, Gleeson JM, Floyd PD, Li L, Rubakhin SS, Sweedler JV (1999) Formation of $N$-pyroglutamyl peptides from $N$-Glu and $N$-Gln precursors in Aplysia neurons. J Neurochem $72: 676-681$.

Gue M, Bueno L (1996) Brain-gut interaction. Semin Neurol $16: 235-243$.

Hewes RS, Snowdeal EC, Saitoe M, Taghert PH (1998) Functional redundancy of FMRFamide-related peptides at the Drosophila larval neuromuscular junction. J Neurosci 18:7138-7151.

Jahan-Parwar B, Fredman SM (1976) Cerebral ganglion of Aplysia: cellular organization and origin of nerves. Comp Biochem Physiol [A] 54:347-357.

Jimenez CR, van Veelen PA, Li KW, Wildering WC, Geraerts WP, Tjaden UR, van der Greef J (1994) Neuropeptide expression and processing as revealed by direct matrix-assisted laser desorption ionization mass spectrometry of single neurons. J Neurochem 62:404-407.

Jing J, Weiss KR (2001) Neural mechanisms of motor program switching in Aplysia. J Neurosci 21:7349-7362.

Kabotyanski EA, Baxter DA, Byrne JH (1998) Identification and characterization of catecholaminergic neuron B65, which initiates and modifies patterned activity in the buccal ganglia of Aplysia. J Neurophysiol 79:605-621.

Kandel ER (1979) Behavioral biology of Aplysia: a contribution to the comparative study of opisthobranch molluscs. San Francisco: W. H. Freeman.

Klein AN, Eisenman JS, Weiss KR, Cropper EC (2000) Changes in ingestive motor programs induced by stimulation of a single sensory neuron in Aplysia. Soc Neurosci Abstr 26:700.

Li L, Moroz TP, Garden RW, Floyd PD, Weiss KR, Sweedler JV (1998) Mass spectrometric survey of interganglionically transported peptides in Aplysia. Peptides 19:1425-1433.

Lloyd PE, Kupfermann I, Weiss KR (1987a) Sequence of small cardioactive peptide A: a second member of a class of neuropeptides in Aplysia. Peptides 8:179-184.

Lloyd PE, Frankfurt M, Stevens P, Kupfermann I, Weiss KR (1987b) Biochemical and immunocytological localization of the neuropeptides FMRFamide, SCPA, SCPB, to neurons involved in the regulation of feeding in Aplysia. J Neurosci 7:1123-1132.

Lloyd PE, Kupfermann I, Weiss KR (1988) Central peptidergic neurons regulate gut motility in Aplysia. J Neurophysiol 59:1613-1626.

Mahon AC, Lloyd PE, Weiss KR, Kupfermann I, Scheller RH (1985) The small cardioactive peptides A and B of Aplysia are derived from a common precursor molecule. Proc Natl Acad Sci USA 82:3925-3929.

Marder E, Christie AE, Kilman VL (1995) Functional organization of cotransmission systems: lessons from small nervous systems. Invert Neurosci 1:105-112.

Miller MW, Beushausen S, Vitek A, Stamm S, Kupfermann I, Brosius J, Weiss KR (1993a) The myomodulin-related neuropeptides: characterization of a gene encoding a family of peptide cotransmitters in Aplysia. J Neurosci 13:3358-3367.

Miller MW, Beushausen S, Cropper EC, Eisinger K, Stamm S, Vilim FS, Vitek A, Zajc A, Kupfermann I, Brosius J, Weiss KR (1993b) The buccalin-related neuropeptides: isolation and characterization of an Aplysia cDNA clone encoding a family of peptide cotransmitters. J Neurosci 13:3346-3357.
Miller MW, Rosen SC, Schissel SL, Cropper EC, Kupfermann I, Weiss KR (1994) A population of SCP-containing neurons in the buccal ganglion of Aplysia are radula mechanoafferents and receive excitation of central origin. J Neurosci 14:7008-7023.

Mutt V (1990) Recent developments in the chemistry of gastrointestinal peptides. Eur J Clin Invest 20 [Suppl] 1:S2-9.

Nielsen H, Engelbrecht J, Brunak S, von Heijne G (1997) Identification of prokaryotic and eukaryotic signal peptides and prediction of their cleavage sites. Protein Eng 10:1-6.

Ono JK, McCaman RE (1992) In situ hybridization of whole-mounts of Aplysia ganglia using non-radioactive probes. J Neurosci Methods 44:71-79.

Phares GA, Lloyd PE (1996) Immunocytological and biochemical localization and biological activity of the newly sequenced cerebral peptide 2 in Aplysia. J Neurosci 16:7841-7852.

Price DA, Greenberg MJ (1977) Structure of a molluscan cardioexcitatory neuropeptide. Science 197:670-671.

Rosen SC, Teyke T, Miller MW, Weiss KR, Kupfermann I (1991) Identification and characterization of cerebral-to-buccal interneurons implicated in the control of motor programs associated with feeding in Aplysia. J Neurosci 11:3630-3655.

Rosen SC, Miller MW, Evans CG, Cropper EC, Kupfermann I (2000) Diverse synaptic connections between peptidergic radula mechanoafferent neurons and neurons in the feeding system of Aplysia. J Neurophysiol 83:1605-1620.

Russo C, Saido TC, DeBusk LM, Tabaton M, Gambetti P, Teller JK (1997) Heterogeneity of water-soluble amyloid beta-peptide in Alzheimer's disease and Down's syndrome brains. FEBS Lett 409:411-416.

Sambrook J, Fritsch EF, Maniatis T (1989) Molecular cloning: a laboratory manual. New York: Cold Spring Harbor Laboratory.

Schaefer M, Picciotto MR, Kreiner T, Kaldany RR, Taussig R, Scheller RH (1985) Aplysia neurons express a gene encoding multiple FMRFamide neuropeptides. Cell 41:457-467.

Scheller RH, Kirk RS (1987) Neuropeptides in identified Aplysia neurons: precursor structure, biosynthesis and physiological actions. Trends Neurosci 10:46-52.

Seidah NG, Chretien M (1999) Proprotein and prohormone convertases a family of subtilases generating diverse bioactive polypeptides. Brain Res 848:45-62.

Strand FL (1999) Neuropeptides: regulators of physiological processes. Cambridge, MA: MIT.

Vilim FS, Cropper EC, Rosen SC, Tenenbaum R, Kupfermann I, Weiss KR (1994) Structure, localization, and action of buccalin B: a bioactive peptide from Aplysia. Peptides 15:959-969.

Vilim FS, Price DA, Lesser W, Kupfermann I, Weiss KR (1996) Costorage and corelease of modulatory peptide cotransmitters with partially antagonistic actions on the accessory radula closer muscle of Aplysia californica. J Neurosci 16:8092-8104.

Warman EN, Chiel HJ (1995) A new technique for chronic single-unit extracellular recording in freely behaving animals using pipette electrodes. J Neurosci Methods 57:161-169.

Worster BM, Yeoman MS, Benjamin PR (1998) Matrix-assisted laser desorption/ionization time of flight mass spectrometric analysis of the pattern of peptide expression in single neurons resulting from alternative mRNA splicing of the FMRFamide gene. Eur J Neurosci 10:34983507. 